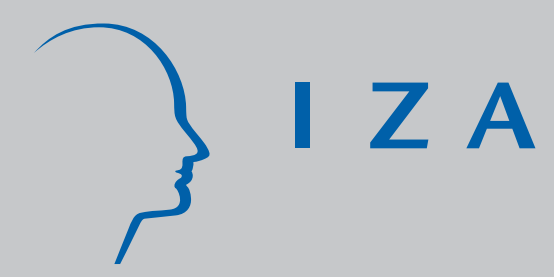

IZA DP No. 1012

A Life-Cycle Model of Outmigration and Economic Assimilation of Immigrants in Germany

Charles Bellemare

February 2004 


\title{
A Life-Cycle Model of Outmigration and Economic Assimilation of Immigrants in Germany
}

\author{
Charles Bellemare \\ CentER, Tilburg University \\ and IZA Bonn
}

\section{Discussion Paper No. 1012 \\ February 2004}

\author{
IZA \\ P.O. Box 7240 \\ 53072 Bonn \\ Germany \\ Phone: +49-228-3894-0 \\ Fax: +49-228-3894-180 \\ Email: iza@iza.org
}

\begin{abstract}
Any opinions expressed here are those of the author(s) and not those of the institute. Research disseminated by IZA may include views on policy, but the institute itself takes no institutional policy positions.

The Institute for the Study of Labor (IZA) in Bonn is a local and virtual international research center and a place of communication between science, politics and business. IZA is an independent nonprofit company supported by Deutsche Post World Net. The center is associated with the University of Bonn and offers a stimulating research environment through its research networks, research support, and visitors and doctoral programs. IZA engages in (i) original and internationally competitive research in all fields of labor economics, (ii) development of policy concepts, and (iii) dissemination of research results and concepts to the interested public.
\end{abstract}

IZA Discussion Papers often represent preliminary work and are circulated to encourage discussion. Citation of such a paper should account for its provisional character. A revised version may be available on the IZA website (www.iza.org) or directly from the author. 
IZA Discussion Paper No. 1012

February 2004

\section{ABSTRACT \\ A Life-Cycle Model of Outmigration and Economic Assimilation of Immigrants in Germany*}

This paper estimates a structural dynamic life-cycle model of outmigration where, in each period, immigrants choose whether to work in the host country, not to work but remain in the host country, or outmigrate. The model incorporates several features of existing life-cycle theories of outmigration but distinguishes itself by introducing uncertainty in about future earnings and preferences which allows immigrants to revise their duration decisions throughout their migration experience. We overcome the problem of not directly observing outmigration movements by using panel attrition as a proxy variable and use a simple method to correct for the fact that part of the attrition is not a consequence of outmigration. Estimates are used to predict changes in life-cycle patterns of outmigration behavior. Estimation results indicate that outmigration does not depend exclusively on earnings differentials. Estimated assimilation rates are found to be robust to selection effects. Immigrants are found to be forward looking decision makers, and simulations show that predicted migration durations are very sensitive to changes in their economic environment and differ considerably from those of a myopic model.

JEL Classification: J61, C61

Keywords: outmigration, structural dynamic programming models

Charles Bellemare

Department of Econometrics

Tilburg University

Warandelaan 2

5000 LE Tilburg

The Netherlands

Email: c.bellemare@uvt.nl

\footnotetext{
* I would like to thank Arthur van Soest, Sabine Kröger, Pierre-Carl Michaud, Christian Dustmann, Jan van Ours and seminar participants at the Immigration Workshop in Tilburg for useful comments and suggestions.
} 


\section{Introduction}

The increasing importance of immigrants leaving their host country, which we refer to as outmigration, is a world wide phenomena (see Dustmann, 2003 and the references therein). The case of Germany is interesting as migration out of Germany has been particularly important in the last decades. Böhning (1987, p.147) estimates that "more than two thirds of the foreign workers admitted to the Federal Republic (of Germany),...have returned", while Glytsos (1988) estimates that of the one million Greeks migrating to West-Germany between 1960 and 1984, 85\% gradually returned home. These massive movements of human capital pose substantial problems for policy makers who must forecast inflows and outflows of immigrants in order to adjust their immigration policies to fit the future needs of their labor markets. Moreover, as recently pointed out by Schultz (1998), active policies to improve the economic integration of immigrants in the host economy may be misguided by existing measures of the economic assimilation of immigrants, as these measures are estimated on possibly non-random samples of immigrants observed not to leave the country. ${ }^{1}$ For both these reasons, a growing body of literature has investigated the motives behind outmigration.

Theories of outmigration typically build upon neo-classical static choice models of migration (Sjaastad, 1962; Harris and Todaro, 1970) by assuming that an immigrant's decision to outmigrate is based on the comparison of his current earnings and those of a potential new destination, often assumed to be the immigrant's home country. Centering the outmigration decision on earnings differentials is motivated by the fact that outmigrants tend to have the lowest labor market performance amongst immigrants in the host country (see Hu, 2000; Lubotsky, 2000 for the case of the United States, and Bellemare, 2003 for the case of Germany). Because static models force migration to be a permanent event, they fail to explain why outmigration is so frequently observed. One way to reconcile the earnings differential paradigm and outmigration has been to assume that immigrants improve their earning position in the home country while being abroad by investing in home-country specific human capital (Dustmann, 1994). In this case, outmigration will occur only if the relative increase in the returns to human capital in the home country is sufficient for the expected earnings in the home country to exceed those in the host country.

However, there is empirical evidence indicating that outmigration does occurs despite persistently higher earnings in the host country. One example is given in Carrington, Detragiache and Vishwanath (1996) who document the important migration of southern blacks to the north of the U.S. between 1915 and 1960, which occurred despite decreasing earnings differentials. In order to reconcile these empirical facts, theories of outmigration have shifted from expected earnings comparisons to expected utility comparisons between two destinations (Djajic and Milbourne, 1988). This subtle change allows outmigration to occur despite having relatively higher earnings in the host country, as long as the marginal utility of consumption is sufficiently higher in the new destination than in the original host country. Several extensions of the expected utility framework have provided new and interesting insights into outmigration behavior. In a recent contribution, Dustmann (2003) shows that a neo-classical approach based on earnings differentials has sufficient flexibility to explain outmigration. Using a life-cycle framework and assuming that the marginal utility of consumption is higher in the home than in the host country, he finds an inverted U shape relation between completed migration durations and earnings in the host country, which suggests that migration durations may in fact decrease when earnings in the host country are high enough, keeping constant earnings in the home country.

A different trend of the literature has placed the emphasis on explaining outmigration decisions with non-pecuniary motives. The main reason for this shift has been the growing evidence,

\footnotetext{
${ }^{1}$ Edin, LaLonde, and Aslund (2000) report evidence that measures of economic assimilation of immigrants in Sweden are sensitive to outmigration.
} 
mainly drawn from the sociological literature, which indicates that expected earnings comparisons alone may not be sufficient to adequately characterize outmigration behavior. Among the most frequently cited non-pecuniary benefits for remaining in the host country are whether or not the spouse or children of immigrants live in the host country, health and income satisfaction, and integration perceptions (Stark, 1998), while credit market rationing in the home country has recently been argued to lead to longer migration durations (Mesnard, 2001).

The vast array of possible determinants of outmigration has yet to be integrated in a unified framework which allows to contrast the relevance of each potential explanation. The role played by uncertainty is critical in building such a framework. In most theories of outmigration discussed above, uncertainty about economic outcomes is either not present at all or introduced in such a way that the duration decisions resulting from an optimization process are deterministic: immigrants simultaneously choose once and for all, at the beginning of their lifetime, their duration of stay in the host country and the levels of consumption in the pre and post migration period. The prediction that immigrants do not revise their intended migration duration during their stay in the host country is questionable in light of the considerable uncertainty immigrants face both before and during the migration period. One important source of uncertainty concerns the difficulty in evaluating labor market prospects in the host country. Pessino (1991) develops a model where an immigrant's uncertainty about his labor market prospects dissipates only after having actually migrated, a feature shown to be sufficient to cause outmigration. The idea that uncertainty is removed upon arrival is intuitively appealing. Yet, it is difficult to conceive that all uncertainty disappears upon an immigrant's arrival in the host country, if only because immigrants generally take up low paid unstable jobs. If uncertainty is perpetually present all through an immigrant's residence in the host country, we would expect immigrants to continuously revise their migration duration in the host country as their information set is updated through time, a feature not yet addressed in the literature reviewed above.

Structural dynamic discrete choice models represent a theoretically appealing way to describe a forward-looking decision maker facing uncertainty about the future. Despite the numerous applications of dynamic discrete choice models, there are to our knowledge no applications to outmigration duration decisions. We believe that one of the main obstacles which has, up to now, prevented the estimation of such models is the difficulty in obtaining accurate micro-level data on outmigration behavior. In a companion paper (Bellemare, 2003), it is shown that there is considerable scope to identify economically relevant outmigration parameters using panel attrition as a proxy variable. Under mild assumptions on the outmigration behavior in the immigrant population, it is shown that the outmigration probability, the conditional work probability and the conditional earnings of outmigrants are all nonparametrically identified using readily available data on immigrant sample attrition. Given identification of the structural parameters of interest, Bellemare (2003) proposes a simple way to extract the information from panel attrition and applies it to estimate a reduced form panel data model of earnings, work and outmigration determination.

In this paper, we specify and estimate the first structural dynamic discrete choice model of earnings, work and outmigration. In our model, forward looking immigrants make sequential decisions on work and outmigration behavior in order to maximize expected discounted lifetime utility. Contrary to most existing life-cycle theories of outmigration, we allow for uncertainty about future work and earnings in both the host and home country all through an immigrant's lifetime. The model introduces this uncertainty while still keeping several important features of the life-cycle literature. Specifically, we allow outmigration to depend on different marginal utilities of consumption and labor market earnings in the host and home country, credit market rationing, and several other non-pecuniary benefits including feelings of social integration, income 
satisfaction, age at immigration and whether the spouse lives in the host country or not. Given these elements are imbedded in our model, we can directly test the validity of some of the motives put forward to explain outmigration.

The model is estimated using 16 years of data drawn from the German Socio-Economic Panel (GSOEP) Public use file. An important characteristic of the Public use file is that outmigration is not observed. We deal with this problem by extending the approach developed in Bellemare (2003) to our structural dynamic framework, which allows to identify and directly test for the relevant determinants of outmigration behavior using available information on immigrant sample attrition, despite that outmigration decisions are not observed.

An additional contribution of our approach is that we endogenize the work decision of immigrants. This has interesting implications for outmigration behavior, as barriers to entry in the host labor market have the potential to lower considerably welfare, thus making outmigration an attractive option. Cohen and Ecktein (2002) estimate a structural model of job training and labor market access and find that improving access to the Israelian labor market gives Russian immigrants higher welfare gains than increasing their potential labor market earnings. The extent to which lower job market access is associated with outmigration has recently been addressed in Bellemare (2003) who finds that immigrants in Germany leaving the country have a 30\% lower probability of working than immigrants who remained in the host country. Moreover, as will be shown in the next section, explicitly modelling the work decision endogenizes measures of immigrant economic assimilation to account for the possible non-randomness of the sample of immigrants who remain in the host country, a fact generally overlooked in the literature.

The estimated model is shown to fit the data well. Immigrants are found to have a time horizon of a little more than 20 years. The outmigration rate is predicted to be approximately $3 \%$ per year, in line with previous estimates based on reduced form approaches. Several explanations of existing life-cycle models appear to be consistent with our data. Specifically, we find that credit-market rationing, satisfaction with income, feelings of social integration and earnings differentials have a significant impact on outmigration decisions. Simulation results show that for some immigrants, predicted migration durations are very sensitive to both changes in returns and in the stock of human capital. Predicted migration durations are found to be very sensitive to whether a myopic rather than a forward-looking model is used. Finally, we find that the estimated assimilation rates are robust to endogeneity of the work and outmigration decisions.

The paper is organized as follows. Section 2 presents the life-cycle model. Section 3 discusses the approach used to estimate the structural model. Section 4 presents the data used in the paper and sketches the state of immigration in Germany and the historical policies that have been implemented to favor and curb immigration flows. Section 5 discusses the results and presents simulations to asses both the performance and the life-cycle implications of the model. Section 6 concludes.

\section{Economic model}

We have a measure of $N$ immigrants in period $t=1$, where immigrant $i$ remains in the panel for $T_{i}$ periods The control variables $\left(d_{i t}^{1}, d_{i t}^{2}, d_{i t}^{3}\right)$ summarize the decisions taken in each period. An immigrant can choose to work in Germany $\left(d_{i t}^{1}=1\right)$, not work but stay in Germany $\left(d_{i t}^{2}=1\right)$ or outmigrate $\left(d_{i t}^{3}=1\right)$. When an immigrant works and stays in Germany, he enjoys non-pecuniary direct (dis)utility $\delta_{i t}^{1}$ and utility from consumption of his labor market earnings $c_{i t}$. The marginal utility of consumption in Germany is denoted by $\theta^{G}$. When he does not work, the immigrant receives non-pecuniary direct utility $\delta_{i t}^{2}$, which reflects utility derived from leisure. Finally, we 
assume that an immigrant who leaves the country finds work and receives direct (dis)utility $\delta_{i t}^{3}$ and utility from consuming his earnings, where the marginal utility of consumption in his home country is denoted by $\theta^{N}{ }^{2}$ Each decision is mutually exclusive (i.e. $d_{i t}^{1}+d_{i t}^{2}+d_{i t}^{3}=1$ ). We assume that outmigration is irreversible which implies that the control variable $d_{i t}^{3}$ acts as a stopping rule. ${ }^{3}$ Every decision is made at the beginning of the period and is based on the information set $\Omega_{i t}$ in period $t$. An immigrant maximizes over a finite horizon $T$ his discounted expected lifetime utility

$$
\boldsymbol{E}\left[\sum_{t=1}^{T} \beta^{t-1}\left(d_{i t}^{1}\left[\delta_{i t}^{1}+\theta^{G} c_{i t}\right]+d_{i t}^{2} \delta_{i t}^{2}+d_{i t}^{3}\left[\delta_{i t}^{3}+\theta^{N} c_{i t}\right]\right) \mid \boldsymbol{\Omega}_{i 1}\right]
$$

by choosing the sequence $\left\{d_{i t}^{* 1}, d_{i t}^{* 2}, d_{i t}^{* 3}\right\}_{t=1}^{T}$. E denotes the expectation taken over the joint distribution of the stochastic state variables (see below) and $\beta \in[0,1]$ is the subjective discount rate. Equation (1) is maximized subject to the immigrant's budget constraint, which is assumed to be satisfied in each period, and is given by

$$
c_{i t}=w_{i t}^{G} d_{i t}^{1}+w_{i t}^{N} d_{i t}^{3}
$$

where $w_{i t}^{G}$ is the log earnings of immigrants in Germany, while $w_{i t}^{N}$ denotes their log earnings in the home country. ${ }^{4}$ The assumption that immigrants do not save is admittedly restrictive. However, $83 \%$ of the immigrants in our sample used in the empirical part of the paper report having not made any savings in the year preceding the interview, a direct implication of their inherently low labor market earnings. Hence, the assumption that immigrants exhaust all their labor market earnings in each period is likely to be realistic for the average immigrant. ${ }^{5}$ The utility functions $\delta_{i t}^{1}, \delta_{i t}^{2}$ and $\delta_{i t}^{3}$ in turn are allowed to depend on individual characteristics

$$
\begin{aligned}
\delta_{i t}^{1}= & \alpha_{10}+\alpha_{11} \text { Sendcash }_{i t}+\alpha_{12} \text { Incomesa }_{i t}+\alpha_{13} \text { Intfeel }_{i t} \\
& +\alpha_{14} \text { Educ }_{i t}+\alpha_{15} \text { Exper }_{i t-1}+\alpha_{16} \text { Exper }_{i t-1}^{2}+\alpha_{17} Y_{\text {sm }}{ }_{i t-1}+\varepsilon_{i t}^{1} \\
\delta_{i t}^{2}= & \varepsilon_{i t}^{2} \\
\delta_{i t}^{3}= & \alpha_{30}+\alpha_{31} \text { Sendcash }_{i t}+\alpha_{32} \text { Incomesa }_{i t}+\alpha_{33} \text { Intfeel }_{i t} \\
& +\alpha_{34} \text { Ageatim }_{i}+\alpha_{35} \text { Wifeinge }_{i t}+\varepsilon_{i t}^{3}
\end{aligned}
$$

Sendcas $h_{i t}$ is a binary indicator taking a value of 1 if the immigrant returns money to the host country. In this paper, we treat this variable as an exogenous proxy for credit market rationing which implicitly assumes that immigrants return money when there is an exogenous need for liquidity in the home country. Ageatim denotes the age at arrival in Germany, Intfeel $_{i t}$ captures sense of being a German, and Wifeinge $e_{i t}$ is a binary indicator taking a value of 1 when the wife of the immigrant lives in Germany. Incomesa $a_{i t}$ denotes reported satisfaction with income earned

\footnotetext{
${ }^{2}$ In this paper, we treat return migration and outmigration as equivalent concepts since most of the outmigration movements are believed to be return movements. However, the model above does not rule out other departure destinations.

${ }^{3}$ In our data, reversible outmigration is negligible (Pannenberg, 1998). In other countries, the assumption of non reversible outmigration is not likely to be satisfied. Jasso and Rosenzweig (1990) find that reversible outmigration of Mexican immigrants living in the United States is particularly important.

${ }^{4}$ Outmigration costs do not enter the budget constraint associated with outmigration, reflecting the fact that the German federal government reimbursed outmigration costs from 1984 to 1992 (see Section 4 for details). We do not model the regime change after 1992.

${ }^{5} \mathrm{~A}$ practical reason for not including savings and borrowing behavior in the model presented here is that this will generally lead to a considerable expansion of the choice set and the state space which, given the associated computational burden, is beyond the scope of this paper.
} 
in Germany. This is included in both the work and the outmigration non-pecuniary benefits to capture the additional utility accruing to financial security which is not due to pure earnings consumption. Educ $c_{i t}$ corresponds to the total number of years of education, Exper it denotes the total number of years of labor market experience while $Y s m_{i t}$ represents the number of years since immigration. These human capital variables are included to capture disutility, or psychic costs, associated with working longer in the host country. For a given level of income, higher educated individuals will have relatively greater disutility from working in the host country if they take on jobs associated with greater responsibilities. Exper ${ }_{i t}$ and $Y s m_{i t}$ are included to capture the possibility that, keeping earnings constant, immigrants with relatively high labor market experience, and those who have been in the host country relatively longer, may suffer greater disutility from working an additional year in the host country. The triplet $\left(\varepsilon_{i t}^{1}, \varepsilon_{i t}^{2}, \varepsilon_{i t}^{3}\right)$ consists of time specific unobserved shocks to utility.

The earnings in Germany are stochastic and depend on the immigrant's past and future decisions

$$
\begin{aligned}
w_{i t}^{G}= & \varphi_{0}+\varphi_{1} \text { Educ }_{i t}+\varphi_{2} \text { Gspeak }_{i t}+\varphi_{3} \text { Unemp }_{i t} \\
& +\varphi_{4} \text { Exper }_{i t-1}+\varphi_{5} \text { Exper }_{i t-1}^{2}+\varphi_{6} \text { Ysm }_{i t-1}+\eta_{i t}^{G}
\end{aligned}
$$

These variables are standard in studies measuring the economic assimilation rate (Borjas, 1999). We further allow the earnings of immigrants to depend on their reported speaking fluency in German Gspeak $i$, and on Unemp $p_{i t}$, the unemployment rate in the province of residence of the immigrant. Section 4 will give a more precise description of these variables. The returns to human capital and the province specific localization are captured by the $\varphi$ parameters while $\eta_{i t}^{G}$ captures unobserved stochastic shocks to earnings. It is important to highlight that the level of education, the labor market experience and the number of years since migration affect the utility of working in the host country via their direct effect on utility $\delta_{i t}^{1}$, and via their indirect effect on the utility from consumption $\theta^{G} w_{i t}^{G}$. In the former case, increases in the stock of human capital have the potential to raise the disutility from work, keeping labor market earnings constant. In the later case, increases in stock of human capital are likely to raise the utility of working in the host country by increasing the utility of consumption.

The earnings in the home country are determined by

$$
w_{i t}^{N}=\gamma_{0}+\gamma_{1} \text { Educ }_{i t-1}+\gamma_{2} \text { Exper }_{i t-1}+\gamma_{3} \text { Exper }_{i t-1}^{2}+\eta_{i t}^{N}
$$

where the $\gamma$ parameters capture the returns to human capital and $\eta_{i t}^{N}$ is an unobserved stochastic shock.

In any given period, $\Omega_{i t}$ contains all state variables entering the earnings and the utility of each choice, as well as all stochastic components $\left(\varepsilon_{i t}^{1}, \varepsilon_{i t}^{2}, \varepsilon_{i t}^{3}, \eta_{i t}^{G}, \eta_{i t}^{N}\right)$. This set is updated over time as decisions are made. The two endogenous state variables, Exper ${ }_{i t-1}$ and $Y_{s m_{i t-1}}$, have the following laws of motion: Exper $_{i t-1}=$ Exper $_{i t-2}+d_{i t-1}^{1}$ and $\left.Y_{s m_{i t-1}}=Y_{s m_{i t-2}}+\operatorname{Max}_{i t-1}, d_{i t-1}^{1}\right]$, with Exper $_{i 0}=Y_{s m_{i 0}}=d_{i 0}^{1}=d_{i 0}^{2}=d_{i 0}^{3}=0$. These laws of motion show that by endogenizing both the decision to work in the home country $\left(d_{i t-1}^{1}=1\right)$ and the migration duration $\left(d_{i t-1}^{1}\right.$ or $\left.d_{i t-1}^{2}=1\right)$, the cumulative number of years of labor market experience and the number of years since immigration are also endogenized. All other variables are assumed to be exogenous. This implicitly assumes that immigrants are in some sense myopic and cannot foresee any updating of their characteristics over time. ${ }^{6}$

\footnotetext{
${ }^{6}$ The most widely used alternative in the dynamic programming literature has been to assume that individuals have rational expectations about the evolution of the exogenous variables over time. Manski (2003) makes a convincing case against the plausibility of the rational expectations assumption in the context of individual decision making. Since it
} 
As discussed in the introduction, endogenizing both the number of years of labor market experience and the number of years since immigration has practical implications in terms of measures of economic assimilation. The most popular measure of assimilation (see Borjas, 1999) is usually defined as the differences in earnings between immigrants and natives with similar observable attributes $x$ which results from one extra year of labor market experience

$$
\frac{\partial E\left(w_{\text {immig }}^{G} \mid x\right)}{\partial t}-\frac{\partial E\left(w_{\text {natives }}^{G} \mid x\right)}{\partial t}
$$

Endogenizing both decisions also implies that the assimilation rate (7) is endogenously determined by past choices. This can be seen by taking the the derivatives of the earnings equation as we increase the number of years of labor market experiences by one

$$
\frac{\partial E\left(w_{\text {immig }}^{G} \mid x\right)}{\partial t}=\varphi_{4}+2 \cdot \varphi_{5} \text { Exper }_{i t-1}+\varphi_{6}
$$

Both derivatives are direct functions of the returns and the level of experience. For immigrants, increasing the number of years of labor market experience also has the effect of increasing the number of years since immigration which is reflected through $\varphi_{6}$. Lalonde and Topel (1992) propose a very different notion of assimilation, which is taken to occur if, between two observationally equivalent immigrants, the one with the greater time in the host country earns more. In terms of our earnings equation, the Lalonde and Topel measure of integration is simply the coefficient of the number of years since migration $\varphi_{6}$. If accounting for the endogeneity of the work and outmigration decisions affect estimates of the returns to labor market experience and to years in the host country, we expect from (7), (??) and (8) that both measures of assimilation will differ from standard linear least squares estimates. The size of the differences will depend on the type and the magnitude of selection into work and outmigration. In the case where immigrant workers who stay in the host country have expected earnings which are greater than those of a randomly selected immigrant, we would expect their returns to labor market experience and to the number of years since immigration to be biased upwards.

\section{Estimation procedure}

This section describes the econometric approach used to estimate the structural model presented above. Our econometric approach assumes that outmigration is not observed, but that panel attrition is. Given some distributional assumptions on the stochastic parts of the model, it is in principle straightforward to test different life-cycle hypothesis by estimating several specifications, each obtained by maximizing the complete likelihood function which combines the choice and earnings data in a single step. Given the numerical burden of estimating a dynamic programming model, this direct approach is computationally demanding. In this paper, we use the three step estimation strategy proposed by van der Klaauw (1996). In the first step, a reduced form dynamic programming model is estimated using the choice data. The parameter estimates of the first step are then used to estimate the parameters of the wage equations, controlling for sample selection due to the decision to work and to remain in the home country. In the third step, a Minimum Distance Estimator (MDE) is used to recover the structural parameters of the economic model. We discuss in more detail each step, starting with the reduced form dynamic programming model.

is unclear whether we would be doing more harm than good by assuming immigrants have rational expectations, we maintain through out the (restrictive) assumption that immigrants have myopic expectations concerning the evolution of all exogenous variables. 
To proceed, we divide $\boldsymbol{\Omega}_{i t}=\left[\boldsymbol{Y}_{i t},\left(\varepsilon_{i t}^{1}, \varepsilon_{i t}^{2}, \varepsilon_{i t}^{3}, \eta_{i t}^{G}, \eta_{i t}^{N}\right)\right]$ into a set $\boldsymbol{Y}_{i t}$ containing all state variables assumed to be observed by the econometrician. When incorporating the earnings equations (5) and (6) in the budget constraint (2), and the budget constraint in the utility function (1), we obtain

$$
\begin{aligned}
& U^{1}\left(\boldsymbol{Y}_{i t}\right)+\epsilon_{i t}^{1}=\alpha_{10}+\alpha_{11} \text { Sendcas }_{i t}+\alpha_{12} \text { Incomesa }_{i t}+\alpha_{13} \text { Intfeel }_{i t} \\
& +\alpha_{14} \text { Educ }_{i t}+\alpha_{15} \text { Exper }_{i t-1}+\alpha_{16} \text { Exper }_{i t-1}^{2}+\alpha_{17} Y_{s m_{i t-1}} \\
& +\theta^{G}\left\{\varphi_{0}+\varphi_{1} E d u c_{i t}+\varphi_{2} \text { Gspeak }_{i t}+\varphi_{3} \text { Unemp }_{i t}+\varphi_{4} \text { Exper }_{i t-1}\right. \\
& \left.+\varphi_{5} \text { Exper }_{i t-1}^{2}+\varphi_{6} Y_{s m_{i t-1}}+\eta_{i t}^{G}\right\}+\varepsilon_{i t}^{1} \\
& =\lambda_{10}+\lambda_{11} \text { Sendcash }_{i t}+\lambda_{12} \text { Incomesa }_{i t}+\lambda_{13} \text { Intfeel }_{i t}+\lambda_{14} \text { Educ }_{i t}+\lambda_{15} \text { Gspeak }_{i t} \\
& +\lambda_{16} \text { Unemp }_{i t}+\lambda_{17} \text { Exper }_{i t-1}+\lambda_{18} \text { Exper }_{i t-1}^{2}+\lambda_{19} Y_{s m_{i t-1}}+\epsilon_{i t}^{1} \\
& U^{2}\left(\boldsymbol{Y}_{i t}\right)+\epsilon_{i t}^{2}=\epsilon_{i t}^{2} \\
& U^{3}\left(\boldsymbol{Y}_{i t}\right)+\epsilon_{i t}^{3}=\alpha_{30}+\alpha_{31} \text { Sendcash }_{i t}+\alpha_{32} \text { Incomes }_{i t}+\alpha_{33} \text { Intfeel }_{i t}+\alpha_{34} \text { Ageatim }_{i} \\
& +\alpha_{35} \text { Wifeinge }_{i t}+\theta^{N}\left\{\gamma_{0}+\gamma_{1} \text { Educ }_{i t}+\gamma_{2} \text { Exper }_{i t-1}+\gamma_{3} \text { Exper }_{i t-1}^{2}+\eta_{i t}^{H}\right\}+\varepsilon_{i t}^{3} \\
& =\lambda_{30}+\lambda_{31} \text { Sendcash }_{i t}+\lambda_{32} \text { Incomesa }_{i t}+\lambda_{33} \text { Intfeel }_{i t}+\lambda_{34} \text { Ageatim }_{i} \\
& +\lambda_{35} \text { Wifeinge }_{i t}+\lambda_{36} \text { Educ }_{i t}+\lambda_{37} \text { Exper }_{i t-1}+\lambda_{38} \text { Exper }_{i t-1}^{2}+\epsilon_{i t}^{3}
\end{aligned}
$$

where the vector $\lambda=\left[\lambda_{10}, \lambda_{11}, \ldots \lambda_{38}\right]^{\prime}$ is used to denote the reduced form parameters of the instantaneous utility functions. We follow van der Klaauw (1996) by assuming that the composite error terms

$$
\begin{aligned}
\epsilon_{i t}^{1} & =\theta^{G} \eta_{i t}^{G}+\varepsilon_{i t}^{1} \\
\epsilon_{i t}^{2} & =\varepsilon_{i t}^{2} \\
\epsilon_{i t}^{3} & =\theta^{H} \eta_{i t}^{H}+\varepsilon_{i t}^{3}
\end{aligned}
$$

are have conditional mean zero and are independently distributed over time and individuals and follow an extreme-value type I distribution.

The model presented above does not admit an analytical solution. Using the terminal conditions and the distributional assumptions on the stochastic components of the model, it is possible to solve numerically for the set of optimal decisions using backward induction for a given set of reduced form parameters $\lambda$ and $\beta$. This is done using Bellman's principle of optimality (Bellman, 1957) which states that the solution of (1) can be decomposed as the solution of $T$ separate problems

$$
\left\{\max _{d_{i t}^{1}, d_{i t}^{2}, d_{i t}^{3}}\left(d_{i t}^{1}\left[V_{t}^{1}\left(\boldsymbol{Y}_{i t}\right)+\epsilon_{i t}^{1}\right]+d_{i t}^{2}\left[V_{t}^{2}\left(\boldsymbol{Y}_{i t}\right)+\epsilon_{i t}^{2}\right]+d_{i t}^{3}\left[V_{t}^{3}\left(\boldsymbol{Y}_{i t}\right)+\epsilon_{i t}^{3}\right]\right)\right\} \text { for all } t=1,2, \ldots, T
$$

where $V_{t}^{j}\left(\boldsymbol{Y}_{i t}\right)$ are value functions associated with choice $j=1,2,3$. The value function associated with the first two decisions $(j=1,2)$ given the information at time $t$ is given by

$$
V_{t}^{j}\left(\boldsymbol{Y}_{i t}\right)=U^{j}\left(\boldsymbol{Y}_{i t}\right)+\beta \boldsymbol{E M a x}\left\{V_{t+1}^{1}\left(\boldsymbol{\Omega}_{i t+1}\right), V_{t+1}^{2}\left(\boldsymbol{\Omega}_{i t+1}\right), V_{t+1}^{3}\left(\boldsymbol{\Omega}_{i t+1}\right) \mid \boldsymbol{Y}_{i t}, d_{i t}^{j}=1\right\}
$$

where EMax represents the expected value of the maximal future value function, where expectation is taken over the triplet $\left(\epsilon_{i, t+1}^{1}, \epsilon_{i, t+1}^{2}, \epsilon_{i, t+1}^{3}\right)$ contained in the information set $\Omega_{i t+1}$. Finally, 
the outmigration decision is a terminal control variable where the value function has the following simple form

$$
V_{t}^{3}\left(\boldsymbol{Y}_{i t}\right)=U^{3}\left(\boldsymbol{Y}_{i t}\right)+\beta \boldsymbol{E}\left\{V_{t+1}^{3}\left(\boldsymbol{\Omega}_{i t+1}\right) \mid \boldsymbol{Y}_{i t}, d_{i t}^{3}=1\right\}
$$

with $E\left\{V_{t+1}^{3}\left(\Omega_{i t+1}\right) \mid \boldsymbol{Y}_{i t}, d_{i t}^{3}=1\right\}$ defined as

$$
\begin{aligned}
& \sum_{j=t+1}^{T} \beta^{j-(t+1)}\left(\lambda_{30}+\lambda_{31} \text { Sendcash }_{i t}+\lambda_{32} \text { Incomesa }_{i t}+\lambda_{33} \text { Intfeel }_{i t}+\lambda_{34} \text { Ageatim }_{i}\right. \\
& \left.+\lambda_{35} \text { Wifeinge }_{i t}+\lambda_{36} \text { Educ }_{i t}+\lambda_{37} \text { Exper }_{i t}+\lambda_{38} \text { Exper }_{i t}^{2}\right)
\end{aligned}
$$

In the finite horizon case, the solution of the value functions (10) are computed by backwards recursion starting in the terminal period $T$. At every time period $t$, the goal is to compute $V_{t}^{j}\left(\boldsymbol{Y}_{i t}\right)$ for every value of $\boldsymbol{Y}_{i t}$ that could enter the choice probabilities at time $t$ or are needed during the recursion in equation (10) to compute the choice-specific value functions in the periods $t-1, t-2, \ldots, 1{ }^{7}$ The primary task is evaluating the EMax functions in equation 10. Given our distributional assumptions, the expected value functions turn out to have a convenient analytical solution (Rust, 1988)

$$
\operatorname{EMax}\left\{V_{t+1}^{1}\left(\boldsymbol{\Omega}_{i t+1}\right), V_{t+1}^{2}\left(\boldsymbol{\Omega}_{i t+1}\right), V_{t+1}^{3}\left(\boldsymbol{\Omega}_{i t+1}\right) \mid \boldsymbol{Y}_{i t}, d_{i t}^{j}=1\right\}=\xi+\log \left(\sum_{k=1}^{3} \exp \left(V_{t+1}^{k}\left(\boldsymbol{\Omega}_{i t+1}\right)\right)\right)
$$

where $\xi$ is Euler's constant. Given we have solved the value function problem for each individual and each time period in our sample for a given set of parameter values, it is straightforward to compute the likelihood function. Each immigrant $i$ is observed for $T_{i}$ time periods. In each time period, we observe for each $i$ in period $t$ the event $\underline{d}_{i}(t)=\left[d_{i t}^{1}, d_{i t}^{2}, d_{i t}^{3}\right]$. The observable choice sequence of $i$ over all sample periods is denoted by $d_{i}=\left[\underline{d}_{i}(t), \ldots, \underline{d}_{i}\left(T_{i}\right)\right]$. The sample likelihood function of the reduced form model is given by

$$
\prod_{i=1}^{N} \operatorname{Pr}\left[\boldsymbol{d}_{i} \mid \lambda, \beta\right]=\prod_{i=1}^{N} \operatorname{Pr}\left[\underline{d}_{i}\left(T_{i}\right) \mid \underline{d}_{i}\left(T_{i}-1\right), \ldots, \underline{d}_{i}(2), \underline{d}_{i}(1)\right] \cdots \operatorname{Pr}\left[\underline{d}_{i}(2) \mid \underline{d}_{i}(1)\right] \operatorname{Pr}\left[\underline{d}_{i}(1)\right]
$$

From equation (11) we see that the choice probability at time $T_{i}$ depends on all past choices of the individual, a fact which is reflected through the information set $Y_{i t}$. In this sense, the structure of the model allows for a general form of state dependance across all alternatives. Given that the Bellman equations have been solved for a given set of parameter values, and given the decision rule (9), the choice probabilities entering (11) can be expressed as functions of the value functions

$$
\operatorname{Pr}\left(d_{i t}^{j}=1 \mid \boldsymbol{Y}_{i t}\right)=\operatorname{Pr}\left(V_{t}^{j}\left(\boldsymbol{Y}_{i t}\right)+\epsilon_{i t}^{j}>V_{t}^{l}\left(\boldsymbol{Y}_{i t}\right)+\epsilon_{i t}^{l} ; \text { for all } l \neq j\right)
$$

Combined with our distributional assumptions, these probabilities have a familiar closed form expression

$$
\begin{aligned}
& \operatorname{Pr}\left(V_{t}^{j}\left(\boldsymbol{Y}_{i t}\right)+\epsilon_{i t}^{j}>V_{t}^{l}\left(\boldsymbol{Y}_{i t}\right)+\epsilon_{i t}^{l} ; \text { for all } l \neq j\right) \\
= & \frac{\exp \left(U^{j}\left(\boldsymbol{Y}_{i t}\right)+\beta \boldsymbol{E M a x}\left\{V_{t+1}^{1}\left(\boldsymbol{\Omega}_{i t+1}\right), V_{t+1}^{2}\left(\boldsymbol{\Omega}_{i t+1}\right), V_{t+1}^{3}\left(\boldsymbol{\Omega}_{i t+1}\right) \mid \boldsymbol{Y}_{i t}, d_{i t}^{j}=1\right\}\right)}{\sum_{k=1}^{3} \exp \left(U^{k}\left(\boldsymbol{Y}_{i t}\right)+\beta \boldsymbol{E M a x}\left\{V_{t+1}^{1}\left(\boldsymbol{\Omega}_{i t+1}\right), V_{t+1}^{2}\left(\boldsymbol{\Omega}_{i t+1}\right), V_{t+1}^{3}\left(\boldsymbol{\Omega}_{i t+1}\right) \mid \boldsymbol{Y}_{i t}, d_{i t}^{k}=1\right\}\right)} .
\end{aligned}
$$

\footnotetext{
${ }^{7}$ As is well known, solving the dynamic programming problem is computationally demanding. Optimizing the likelihood function presented below took more than one month on a $2.66 \mathrm{GHz}$ pentium 4 processor. On the other hand, maximization of the likelihood function assuming immigrants are myopic agents took less than a minute.
} 
So far, we have assumed that $d_{i t}^{3}$ was perfectly observed. However, in most data sets including the one which will be used in the empirical application, outmigration is not observed. Instead, we observe the panel attrition indicator $d_{i t}^{30}$ which takes a value of 1 when the immigrant drops out of the panel and 0 otherwise. Hausman, Abrevaya and Scott-Morton (1998) have shown that measurement error of a binary left hand side variable can lead to severely biased parameters and variance estimates in non-linear models. Because the dynamic programming model used in this paper is highly non-linear, measurement error is a non-trivial issue. We deal with the partial observability of outmigration in our data by extending the method proposed by Bellemare (2003). The method rests on the idea that an immigrant who outmigrates necessarily leaves the panel, which suggests that panel attrition carries some information on outmigration behavior. To extract the information on outmigration contained in panel attrition, we start by expressing the attrition probability as

$$
\begin{aligned}
\operatorname{Pr}\left(d_{i t}^{3 o}=1 \mid \boldsymbol{Y}_{i t}\right)= & \operatorname{Pr}\left(d_{i t}^{3 o}=1 \mid d_{i t}^{3} \neq 1\right) \operatorname{Pr}\left(d_{i t}^{3} \neq 1 \mid \boldsymbol{\Upsilon}_{i t}\right) \\
& +\operatorname{Pr}\left(d_{i t}^{3 o}=1 \mid d_{i t}^{3}=1\right) \operatorname{Pr}\left(d_{i t}^{3}=1 \mid \boldsymbol{Y}_{i t}\right) \\
= & \alpha_{3,12}\left\{\operatorname{Pr}\left(d_{i t}^{1}=1 \mid \boldsymbol{\Upsilon}_{i t}\right)+\operatorname{Pr}\left(d_{i t}^{2}=1 \mid \boldsymbol{\Upsilon}_{i t}\right)\right\} \\
& +\operatorname{Pr}\left(d_{i t}^{3}=1 \mid \boldsymbol{\Upsilon}_{i t}\right)
\end{aligned}
$$

where $\alpha_{3,12} \equiv \operatorname{Pr}\left(d_{i t}^{30}=1 \mid d_{i t}^{3} \neq 1\right)$ represents the probability of observing that an immigrant leaves the panel given that he remained in Germany, either working or not. ${ }^{8}$ The last equality in (12) follows from the fact that $\operatorname{Pr}\left(d_{i t}^{30}=1 \mid d_{i t}^{3}=1\right)=1$ whereby an immigrant who outmigrates will leave the panel with probability 1 . The parameter $\alpha_{3,12}$ can be directly incorporated in the likelihood function above and estimated. ${ }^{9}$ In the end, we solve the following problem

$$
\max _{\lambda, \beta, \alpha_{3,12}} \log \left(\prod_{i=1}^{N} \operatorname{Pr}\left[\boldsymbol{d}_{i} \mid \lambda, \beta, \alpha_{3,12}\right]\right)
$$

The procedure used above is motivated on the basis that the information on outmigration behavior contained in panel attrition can be sizeable. The informational content of panel attrition is summarized in the following Proposition

Proposition 1 If $\alpha_{3,12}$ is independent of observable characteristics and there exists a $\tau_{i t}$ such that $\operatorname{Pr}\left(d_{i t}^{3}=1 \mid \boldsymbol{Y}_{i t}=\boldsymbol{\tau}_{i t}\right)=0$, both $\operatorname{Pr}\left(d_{i t}^{3}=1 \mid \boldsymbol{Y}_{i t}\right)$ and $\boldsymbol{E}\left\{w_{i t}^{G} \mid d_{i t}^{3}=1, \boldsymbol{Y}_{i t}\right\}$ are nonparametrically identified for all $\mathrm{Y}_{i t}$.

\footnotetext{
${ }^{8}$ This is closely related to the class of discrete choice models where the endogenous discrete outcome is either misclassified or misreported. See Bound, Brown and Mathiowetz (2001) for a survey of this literature. Our approach differs from this literature as one of the realizations of the binary outcome is measured without error.

${ }^{9}$ The individual likelihood contribution of an immigrant can be written using (12) and using the fact that the remaining event $\operatorname{Pr}\left(d_{i t}^{1}=1 \cup d_{i t}^{2}=1 \mid \boldsymbol{Y}_{i t}\right)$ is given by

$$
\begin{aligned}
\operatorname{Pr}\left(d_{i t}^{1}=1 \cup d_{i t}^{2}=1 \mid \boldsymbol{Y}_{i t}\right)= & \operatorname{Pr}\left(d_{i t}^{1}=1 \cup d_{i t}^{2}=1 \mid d_{i t}^{1}=1 \cup d_{i t}^{2}=1\right) \operatorname{Pr}\left(d_{i t}^{1}=1 \cup d_{i t}^{2}=1 \mid \boldsymbol{Y}_{i t}\right) \\
& +\underbrace{\operatorname{Pr}\left(d_{i t}^{1}=1 \cup d_{i t}^{2}=1 \mid d_{i t}^{3}=1\right)}_{=0} \operatorname{Pr}\left(d_{i t}^{3}=1 \mid \boldsymbol{Y}_{i t}\right) \\
= & \left(1-\alpha_{3,12}\right) \operatorname{Pr}\left(d_{i t}^{1}=1 \cup d_{i t}^{2}=1 \mid \boldsymbol{Y}_{i t}\right)
\end{aligned}
$$

where we made use of the fact that $\operatorname{Pr}\left(d_{i t}^{1}=1 \cup d_{i t}^{2}=1 \mid d_{i t}^{1}=1 \cup d_{i t}^{2}=1\right)=1-\alpha_{3,12}$.
} 
Proof. See Bellemare (2003)

The Proposition shows that if there exist immigrants with observable characteristics $\tau_{i t}$ such that their outmigration probability is zero, panel attrition is sufficiently informative to nonparametrically identify all the economically relevant outmigration parameters. ${ }^{10}$ As a consequence, this identification result justifies the use of sample attrition as a baseline proxy variable for outmigration. ${ }^{11}$ The assumption that there exists a subpopulation of immigrants with observable characteristics such that the probability of outmigration is zero can be checked after having estimated the model by computing the predicted outmigration probabilities for each immigrant. Intuitively, this condition is likely to be satisfied in countries where a substantial part of the immigrant population is observed to remain in the country. We will see in section 4 that more than $25 \%$ of immigrants remained in the sample between 1985 and 1999. Results of Proposition 1 also suggest that it is possible to extract the relevant outmigration parameters using some nonparametric estimator. This approach is not practical in the present context as our main goal is to estimate our structural economic model which is generically nonparametrically under-identified. ${ }^{12}$ However, this nonparametric identification result gives a sound motivation to the approach presented here and suggests that parametric estimates of the outmigration probability should not depend heavily on our parametric assumptions.

The reduced form estimates of the dynamic programming model are used to estimate the earnings equation (5) correcting for selectivity due to work and attrition. Dubin and McFadden (1984) show that when the errors are extreme-valued and under the assumption that the conditional expectation $\boldsymbol{E}\left(\eta_{i t}^{G} \mid \varepsilon_{i t}^{1}, \varepsilon_{i t}^{2}, \varepsilon_{i t}^{3}\right)$ is linear in $\varepsilon_{i t}^{1}, \varepsilon_{i t}^{2}$ and $\varepsilon_{i t}^{3}$, the conditional expected earnings of immigrants who work in Germany is given by

$$
\begin{aligned}
\boldsymbol{E}\left(w_{i t}^{G} \mid d_{i t}^{1}=1, \boldsymbol{Y}_{i t}\right)= & \varphi_{0}+\varphi_{1} \text { Educ }_{i t}+\varphi_{2} \text { Exper }_{i t-1}+\varphi_{3} \text { Exper }_{i t-1}^{2}+\varphi_{4} Y_{s m_{i t-1}} \\
& +\varphi_{5} \text { Gspeak }_{i t}+\varphi_{6} \text { Unemp }_{i t} \\
& +\tau_{2}\left[\frac{\operatorname{Pr}\left(d_{i t}^{2}=1 \mid \boldsymbol{Y}_{i t}\right) \log \left(\operatorname{Pr}\left(d_{i t}^{2}=1 \mid \boldsymbol{Y}_{i t}\right)\right)}{1-\operatorname{Pr}\left(d_{i t}^{2}=1 \mid \boldsymbol{Y}_{i t}\right)}+\log \left(\operatorname{Pr}\left(d_{i t}^{1}=1 \mid \boldsymbol{Y}_{i t}\right)\right)\right] \\
& +\tau_{3}\left[\frac{\operatorname{Pr}\left(d_{i t}^{3}=1 \mid \boldsymbol{Y}_{i t}\right) \log \left(\operatorname{Pr}\left(d_{i t}^{3}=1 \mid \boldsymbol{Y}_{i t}\right)\right)}{1-\operatorname{Pr}\left(d_{i t}^{3}=1 \mid \boldsymbol{Y}_{i t}\right)}+\log \left(\operatorname{Pr}\left(d_{i t}^{1}=1 \mid \boldsymbol{Y}_{i t}\right)\right)\right]
\end{aligned}
$$

The parameters of this equation can be consistently estimated using OLS provided we have consistent estimates of the choice probabilities which enter the selection terms (see van der Klaauw, 1996). Here, we replace $\operatorname{Pr}\left(d_{i t}^{1}=1 \mid \boldsymbol{Y}_{i t}\right), \operatorname{Pr}\left(d_{i t}^{2}=1 \mid \boldsymbol{Y}_{i t}\right)$ and $\operatorname{Pr}\left(d_{i t}^{3}=1 \mid \boldsymbol{Y}_{i t}\right)$ by estimates from the reduced form dynamic programming model.

\footnotetext{
${ }^{10}$ Bellemare (2003) shows that the nonparametric identification result also holds, with minor modification, if $\alpha_{3,12}$ depends on observable characteristics.

${ }^{11}$ Several approaches have been proposed to identify and test for outmigration bias despite not directly observing outmigration. Jasso and Rosenzweig (1990) heuristically document the importance of outmigration in the U.S. by comparing the skill composition of specific cohorts over time. However, their approach allows to identify the direction but not the magnitude of the outmigration selectivity. Recent attempts have tried to combine longitudinal and crosssectional data $(\mathrm{Hu}, 2000 ;$ Lubotsky, 2000). These studies face several problems, notably censoring of the earnings records, representativeness of the sample of participants in the longitudinal data sets, little information on human capital of migrants and partial observation of some key variables. None of these approaches allow to recover either the conditional work probability or the conditional earnings of outmigrants.

${ }^{12}$ The degree of under-identification in discrete dynamic programming models is discussed in Rust (1994) and Magnac and Thesmar (2002).
} 
Finally, in the third stage, given consistent estimates of $\left[\widehat{\beta}, \widehat{\alpha}_{3,12}, \widehat{\lambda}^{\prime}, \widehat{\varphi}^{\prime}, \widehat{\tau}_{2}, \widehat{\tau}_{3}\right]^{\prime} \equiv \widehat{p}$, we can obtain consistent estimates of the structural parameters $\psi$ by using a minimum distance estimator (Chamberlain, 1984). We define the MDE as

$$
\min _{\psi}(\widehat{\boldsymbol{p}}-g(\boldsymbol{\psi}))^{\prime} \boldsymbol{C}^{-1}(\widehat{\boldsymbol{p}}-g(\boldsymbol{\psi}))
$$

where the function $g$ imposes on the reduced form parameters the restrictions specified by the structural model. ${ }^{13} C$ denotes the covariance matrix of $\hat{p}$ which can be computed using the estimated covariance matrices and the outer-product of the scores from the first two rounds (van der Klaauw, 1996). The resulting estimate of $\psi, \widehat{\psi} \stackrel{\text { a.s }}{\rightarrow} \psi_{0}$ and

$$
\sqrt{N}\left(\widehat{\psi}-\boldsymbol{\psi}_{0}\right) \stackrel{d}{\rightarrow} N\left(0,\left(\boldsymbol{H}^{\prime} \boldsymbol{C}^{-1} \boldsymbol{H}\right)^{-1}\right)
$$

where $\boldsymbol{H}=\partial g(\boldsymbol{\psi}) / \partial \boldsymbol{\psi}^{\prime}$ and $\boldsymbol{\psi}_{0}$ is the true value of $\boldsymbol{\psi}$.

We now briefly discuss identification of the structural parameters. The discount factor $\beta$ is identified from the assumption that time preferences are additive. The parameters of the earnings equation in the host country are identified from earnings data. Given these and the fact that because the utility of leisure is normalized to zero, reduced form $\lambda$ parameters are identified from the choice data, thus $\theta^{G}$ is identified from the exclusion of Gspeak $k_{i t}$ and Unemp $p_{i t}$ from the direct utility of working. Moreover, the identification of the reduced form $\lambda$ parameters also implies that $\left\{\alpha_{31}, \alpha_{32}, \alpha_{33}, \alpha_{34}, \alpha_{35}\right\}$ are identified. Identification of the parameters of the earnings function in the home country (6) would require data on immigrant earnings upon their return. Because our data does not contain this information (see section 4), we cannot separately identify $\theta^{N}$ and all $\gamma$ parameters. Instead, our data identifies $\left\{\alpha_{30}+\theta^{N} \gamma_{0}, \theta^{N} \gamma_{1}, \theta^{N} \gamma_{2}, \theta^{N} \gamma_{3}\right\}$ which nevertheless reveals some information on the coefficients of the earnings equation of $w_{i t}^{N}$. More precisely, all four $\theta^{N} \gamma$ parameters are non-zero if and only if $\theta^{N}$ and the parameter $\gamma$ are separately non-zero. Under the plausible assumption that $\theta^{N}>0$, the signs of the $\gamma$ parameters as well as ratios of $\gamma_{j}$ are identified.

Given the parameters which are identified, some of the existing outmigration theories can be tested in a straightforward way. The neo-classical assumption that outmigration decisions are entirely based on earnings differentials can be evaluated by testing whether the parameters determining the non-pecuniary benefits in equations (3) and (4) are jointly equal to zero. The hypothesis that immigrants are myopic decision makers can be evaluated by testing whether the discount factor $\beta$ is equal to zero. The importance of credit market rationing can be evaluated by testing whether the coefficients of Sendcash $h_{i t}$ entering the non-pecuniary benefits of work and outmigration, and whether returning money has a net positive effect on outmigration can be seen by simulating choice sequences (section 5). It is interesting to test the hypothesis put forward in Dustmann (2003) which says that migration durations may in fact decrease if the earnings in the host country increase, keeping earnings in the home country fixed. This test is a simple comparative exercise and does not require separate identification of the earnings function parameters in (6) and the marginal utility of consumption in the home country (they are taken as given in the comparative static exercise).

\footnotetext{
${ }^{13}$ Examples of restrictions are $\lambda_{10}=\alpha_{10}+\theta^{G} \varphi_{0}$ and $\lambda_{13}=\theta^{G} \varphi_{2}$.
} 


\section{Background and Data}

The historical inflow of immigrants in Germany has never been stable. The period of post-war adjustment saw a tremendous decolonization of former Soviet economies. For example, 12 million Germans left eastern Europe by 1950, with 8 million coming to West-Germany (Zimmermann, 1995; pp.46). Between 1955 and 1973, the strong economic development across northern Europe paved the way to an increase demand for labor and led to a large inflow of migrants mainly from the southern European countries and Turkey. The percentage of foreign born workers employed in West-Germany increased from $0.6 \%$ in 1957 to $11.2 \%$ in 1973.

Bilateral recruitment agreements between Germany and Italy, Spain, Greece, Turkey, Portugal and Yugoslavia in the 1950s and 1960s reduced the migrants' cost of migration considerably: workers entered Germany with a one year working contract, they could not be dismissed during the first year, travel costs were reimbursed, and employers had to provide accommodation. After the oil shock in 1973, recruitment stopped, but families and dependents of the immigrants living in Germany continued to flow in. In 1984, in light of difficult labor market conditions, the government issued a repatriation scheme which gave financial incentives to outmigrate. Financial incentives were amongst the main instruments. All workers who had recently become unemployed could apply for return package which included a lump sum subsidy and an allowance for each child. Access to these programs was restricted to certain nationalities and mostly immigrants of Turkish and Portuguese nationality participated; see Dustmann (1996) for more details. In 1999, the Nationality Act was amended with the objective to facilitate the naturalization of foreigners entering the country and to adapt immigration flows to the requirements of the German economy (OECD, 2001). One immediate action of the government was to vote the Nationality Code in July 1999. This code attempts to make it easier for foreigners to obtain the German nationality.

The data used in this paper is extracted from the immigrant sample of the public use file of the GSOEP and covers the 1985-1999 period. The sample consists of an oversample of immigrants living in West-Germany coming from countries which had signed a bilateral migration agreement with Germany in the 1950s and 1960s namely Greece, Italy, Spain, Turkey and Yugoslavia ${ }^{14}$. Data on speaking fluency, feelings of being socially integrated, intended length of stay and remittances where given in consecutive waves from 1984 until 1987. Starting in 1987, this information was gathered every other year. In order to keep a constant time interval between observations, we have chosen to keep the 8 waves of the panel where detailed information on immigrants was available, each spanned by one year, starting in 1985 and ending in 1999. We restrict our attention to males between 18-64 years of age during the 1985 and 1999 period. Excluded from the sample are individuals who died during the observation period and individuals who gave incomplete information on any single variable entering the empirical model in any of the 8 waves. This leaves us with a sample of 732 immigrants starting in 1985.

Figure 1 presents the proportions of immigrants in the sample which were working, not working or left the panel in each wave from 1987 to $1999 .{ }^{15}$ Changes over time can be broken down to three sub-periods. The 1987 to 1991 period saw the percentage of working immigrants increase from $68 \%$ in 1987 to $73 \%$ in 1991 . At the same time, the proportion of non-working immigrants increased from $12 \%$ in 1987 to $16 \%$ in 1991. The movements in employment and unemployment were matched by a general decline in the attrition rates, from $20 \%$ in 1987 to just over $10 \%$ in 1991 . The period from 1991 to 1995 is characterized by the general economic downturn which followed reunification. The percentage of the immigrant population working declined steadily to $58 \%$ in

\footnotetext{
${ }^{14}$ Immigrants of Portuguese nationality are not included in the panel.

${ }^{15}$ The 1985 choice data is omitted from the figure as no attrition took place by construction.
} 
1995 while the proportion of non-workers and the proportion of who left the panel increased respectively by 8 and 6 percentage points. It is impossible to tell from this raw data whether the rise in attrition, which occurred during this period of economic austerity, was caused by increasing outmigration flows or due higher non-response rates due to migration within the country. In the final sub-period (1995-1999), the proportion of working immigrants slightly increased to $63 \%$ in 1997 before declining to $58 \%$ in 1999, while the proportion of non-working immigrants increased to $26 \%$ in 1997 before falling to $22 \%$ in 1999 . As a result, the attrition rate decreased in 1997 before increasing in 1999.

Table 1 gives variable descriptions and summary statistics for the 1985 and 1999 waves. We see that the average age of immigrants was 39.8 years in 1985 and 44.5 years in 1999, a five year increase over a 14 year interval which indicates that the relatively older immigrants left the panel. The average number of years of labor market experience increased by 3.3 years over the 14 year period, which is consistent with the fact that the proportion of working immigrants fell in the 1990's.

Most immigrants migrated to Germany early in their productive lives, a fact reflected by an average age at immigration of nearly 24 years, a figure consistent through out the observation period, indicating that most immigrants were in the age to autonomously decide to move to Germany. The average year of immigration in our data was 1969 in the 1985 wave, but increased to 1979 in the 1999 wave, indicating that the earlier cohorts are most susceptible to have dropped out of the panel. As the earlier cohorts contain the migrants with the higher number of years since migration in 1985, it is not surprising to see that average years since immigration increases relatively less than the 14 year time span, passing from 15.75 in 1985 to 19.63 in 1999. Reported feelings on integration in the German society and reported speaking fluency improved over time while health satisfaction deteriorated, the latter likely capturing an aging effect. Finally, $73 \%$ of immigrants reported having a spouse living outside Germany in 1985 while as little as 1\% still do so in 1999. This severe drop can be interpreted in two different ways. First, spouses may have eventually migrated to Germany during the time period. Second, it might be that immigrants whose spouse was living abroad were more likely to outmigrate.

\section{Estimation results for the structural model}

The model was estimated by setting the time horizon, $T$, at 65 years of age. In this section, we will compare two specifications, a myopic (static) model which sets $\beta$ equal to 0 and a forwardlooking (dynamic) model where $\beta$ is estimated. In the later case, $\beta$ converged to an estimated value of 0.655 , which is statistically significant at the $5 \%$ level, indicating that immigrants are reasonably forward looking decision makers. Accordingly, we will focus our analysis of the results using the forward looking specification and make references to the myopic model when necessary.

Structural estimates and asymptotic standard errors of the myopic and forward-looking models are presented in Table 2. ${ }^{16}$ All parameter estimates are fairly similar across both models. Starting with the estimates of the earnings equation in Germany, we find the usual positive effects of the number of years of education and labor market experience, and the concave relationship between earnings and labor market experience in both the myopic and forward-looking models. Furthermore, increases in the number of years since migration and improvements in the speaking fluency of immigrants have a positive and significant effect on labor market earnings. Living in

\footnotetext{
${ }^{16}$ The corresponding estimates of the reduced form choice and earnings parameters are presented in Table 5 in the appendix.
} 
provinces of Germany with relatively higher unemployment rates has a small but significant negative influence on earnings of immigrants, reflecting the presence of labor market externalities. Immigrant earnings are found to increase by $1.1 \%$ with every extra year spent in the host country, which suggest that economic assimilation in the sense of LaLonde and Topel (1992) is taking place.

As we mentioned in the introduction, it has recently been argued that this and other measures of assimilation may be biased due to the non-randomness of the population of working immigrants who remain in the host country. This hypothesis has up till now received little empirical scrutiny. However, when assimilation is defined along the lines of LaLonde and Topel or according to (7), the impact of selection can be tested easily by comparing the slope parameters associated with the number of years of labor market experience and the number of years since immigration of our structural model and the OLS estimator. The last two columns of Table 2 present OLS estimates of the earnings equation. We find that both the first and second order terms of the number of years of labor market experience, and the returns to an extra year of stay in the host country are not statistically different between both models, which clearly suggest that measures of economic assimilation, either defined in terms of equation (7) or in terms of LaLonde and Topel (1992), are robust to endogeneity of the work and outmigration decisions. ${ }^{17}$ Similar robustness properties were found in the reduced form model of Bellemare (2003) which uses the same data. The main difference between the reduced form approach of that paper and the structural approach presented in this paper is that in the former case, selection bias was modelled as driven by correlated time persistent unobserved heterogeneity across the earnings, work and outmigration behavior. In the structural model here, selection is entirely based on observable accumulation of human capital factors.

We now turn to the estimates of the utility function parameters in Table 2. Neo-classical models of outmigration assume that outmigration is exclusively driven by earnings differentials between the host and home country. Hence, the relevant null hypothesis to test is whether all nonpecuniary rewards entering $\delta_{i t}^{1}$ and $\delta_{i t}^{3}$ are jointly equal to zero. Our empirical results show that this null hypothesis is strongly rejected. Increased satisfaction with income, higher feelings of being integrated in Germany and sending money back to the native country all significantly increase the utility of working in Germany relative to not working but remaining in Germany. Sending money back to the native country also has a significant and positive effect on the utility of outmigration, relative to not working. Because $\alpha_{12}>\alpha_{32}$, credit market rationing has a negative net effect on outmigration in the myopic model. ${ }^{18}$ Satisfaction with income is found not to affect $\delta_{i t}^{3}$, the utility of outmigration relative to not working in the host country. Given that higher satisfaction with income was shown to lead to increases in the utility of working in the host country, it is clear that this will lead to a lower outmigration probability. Finally, psychic costs of working were captured by including education, labor market experience and years since migration in the direct utility of working. We find that keeping earnings constant, the disutility from work in the host country increases with the number of years of education, which can be explained by the fact that individuals with higher levels of education tend to take jobs with more responsibilities, raising their psychic costs of working. Similarly, we find that the psychic costs quickly increase with the number of years of labor market experience. Because the marginal earnings gain from an extra year of labor market experience is small at high values of labor market experience while at the same time psychic costs are at their highest, we expect that immigrants with relatively higher migration and work experience retire progressively from the labor force. Furthermore, we find that the disutility from working in the host country increases with the migration duration. Because the increase

\footnotetext{
${ }^{17}$ Formally, to asses the impact of endogeneity on assimilation of the type defined in equation (7) would require using earnings equation parameters for Germans which are estimated using a dynamic model which endogenizes the number of years of labor market experience. We leave this task for future work.

${ }^{18}$ The effect of credit market rationing in a dynamic model will be evaluated below.
} 
in earnings which accrues to one extra year in the host country are small, this suggests that the outmigration probability may in fact increase as the number of years since immigration increase, despite that assimilation, in the sense of Lalonde and Topel (1992), is taking place ${ }^{19}$. The marginal utility of consumption is positive and significant, which indicates that earnings differentials affect the work and the outmigration decisions. Some other results of interest are that higher age at immigration is associated with a higher utility of outmigrating, which could reflect that older migrants have less time to integrate and establish solid roots and networks in Germany.

Turning now to parameter estimates of the earnings equation in the home country, it is important to recall that without observations on the earnings of outmigrants in the home country, the returns to human capital in the home country are not separately identified from $\theta^{N}$, nor are they separately identified from direct effects on utility $\delta_{i t}^{3}$ such as those found to affect the utility of working in Germany. However, under the realistic assumption that $\theta^{N}$ is positive ${ }^{20}$ and the (a priori strong) assumption that the level of education and the number of years of labor market experience in the host country do not affect the direct utility of outmigration other than through earnings, the signs of $\gamma_{1}, \gamma_{2}$ and $\gamma_{3}$ are identified. If both assumptions hold jointly, we expect that education enters positively $\left(\gamma_{1}>0\right)$, while experience enters with the usual concave relationship $\left(\gamma_{2}>0, \gamma_{3}<0\right)$. If keeping earnings constant individuals with higher levels of education or a higher number of years of labor market experience also suffer greater disutility from outmigrating, then estimated signs of the parameters may be overturned. We find that education has a familiar positive and statistically significant effect on outmigration, indicating that more educated immigrants have higher utility from outmigrating relative to not working but remaining in the host country. However, contrary to what one would expect from a typical earnings profile, the relationship between the number of years of labor market experience and outmigration utility is convex rather than concave. Starting from no labor market experience, the utility of outmigration is predicted to rapidly decrease as labor market experience increases, reaching a minimum at 25.43 years of labor market experience. For an immigrant with labor market experience higher than 25.43 years, the utility of outmigration progressively increases as years of labor market experience are accumulated. One possible way to explain this convex relation is that $\theta^{N}$, instead of being positive, is negative. If this were the case, we would find that education has a negative rather than a positive effect of earnings, which is rather unlikely. Thus, it is more probable that the convex pattern reflects unidentified psychic costs/gains associated with outmigration similar to those found in the direct utility of working in the host country.

Our inferences on outmigration behavior rely on an identification strategy which allowed us to extract information on outmigration behavior from sample attrition by introducing in the likelihood function the parameter $\alpha_{3,12}$ which accounts for the possibility that attrition does not always lead to outmigration. The estimated value of $\alpha_{3,12}$ is 0.102 , which represents the probability of attrition which is not due to outmigration. The difference between the overall attrition rate, of the level of $17 \%$ per two years, and $\alpha_{3,12}$, suggests an average outmigration rate of $6 \%$ per two years, or $3 \%$ per year, remarkably close of the corresponding value reported in Bellemare (2003). The robustness of this value to whether we estimate a reduced form or a structural model, or whether we estimate a structural myopic model or a forward-looking model, is an indirect indication that nonparametric identification of this quantity holds. This belief is further reinforced by the simulation evidence presented below which indicates that the majority of immigrants in our sample are pre-

\footnotetext{
${ }^{19}$ Recall that Lalonde and Topel (1992) define assimilation as the effect on one extra year of experience in the host country, which corresponds to the coefficient of the number of years since immigration entering the earnings equation in Germany.

${ }^{20}$ The literature (see e.g. Djajic and Milbourne, 1988; Stark, 1998) typically assumes that $\theta^{N}>\theta^{G}$. Given our estimated value of $\theta^{G}$ is 4.906 (see table 2), it follows that $\theta^{N}>0$ will hold.
} 
dicted to have an outmigration probability close to 0 , satisfying one of the essential requirements for nonparametric identification of $\alpha_{3,12}$. To interpret the value of $\alpha_{3,12}$, it is useful to compare the average attrition rate in our sample of immigrants with that of a representative sample of native Germans. Table 3 is taken from Bellemare (2003) and presents the attrition rates per wave for both immigrants and native German samples. Averaging over the sample period, we find that the attrition rate in the sample of Germans is $11.6 \%$ (per two years) and $17.2 \%$ in the immigrant sample. If the proportion of immigrants leaving the panel but remaining in Germany is of the same magnitude to that of Germans, than the difference between attrition rates would represent the average outmigration rate. We do not have direct information indicating that immigrants have the same normal attrition rate than natives. However, apart from outmigration and deaths, panel attrition occurs either because individuals decide to stop participating in the survey project, or individuals move within Germany and cannot be tracked by the survey institution. Clark and Drever (2001) show that immigrants in the GSOEP sample are not more likely to move within Germany than natives while Pischke and Velling (1997) show that immigrants in the western parts of Germany live in regions with a high concentration of ethnic minorities. Both results imply that, if anything, immigrants are easier to track than natives; hence the proportion of immigrants dropping out and staying in Germany should be of similar magnitude to that of Germans and suggests that $\alpha_{3,12}$ should be no greater than $11.6 \%$, which is what we find in the data.

Before illustrating the implications of these estimates in terms of individual differences in lifecycle patterns of outmigration, we first present evidence that the model explains our data reasonably well. We do so by simulating for each individual 1000 choice sequences from the first period to each individual's final observation period. Yearly predicted proportions for each of our three decisions were then obtained by averaging simulated choices in each period over all draws and all individuals. The top panel of Figure 2 shows the corresponding simulated (S) and real (R) frequencies of the choice to work in Germany along with the choice to stay in Germany without working. We see that our model fits the data well over our time horizon. Specifically, the model is able to capture both the decline in the work participation and the associated rise in the proportions of non-workers which occurred after 1991. The bottom panel of Figure 2 shows the simulated and real attrition rates together with the predicted outmigrated rate for each wave. Our model slightly under predicts attrition in 1987 and 1989 but fits the data well after that. The under prediction at the start of the sample period is consistent with the fact that attrition rates for native Germans were also higher in the first waves of the panel (see Bellemare, 2003), a fact which can be traced back to the early survey methodology (Pannenberg, 1998). Finally, the predicted outmigration rate rises from $2.5 \%$ in 1987 to $3.5 \%$ in 1995, at the peak of the economic downturn. Subsequently, the outmigration rate is predicted to fall slightly from 1995 onwards, a drop which is consistent with the stabilization of the increase in the proportion of immigrants' unemployed.

\subsection{Implications for life-cycle behavior}

The estimates in Table 2 show that both the myopic and forward looking models yield very similar parameter estimates. However, because changes in model parameters will additionally perturb the Emax functions entering the value functions of the forward looking model, and because immigrants are found to be forward looking, predicted life-cycle patterns may differ substantially across both models. In this section, we perform some comparative static exercises to quantify these differences. As the outmigration probability of an average sample immigrant is very low, performing comparative static exercises on a representative immigrant does not induce sufficient variation in his migration behavior to appreciate the implications of the model. Instead, we take as a benchmark an immigrant at the margin of moving and staying in Germany. He his defined as a 30 year old immigrant, who migrated to Germany four years ago, has 10 years of education, 
8 years of experience, does not return money to his native country, speaks below average German ( 4 on the scale from 1 to 5), is not married, has a reported satisfaction with income of 3 (on the scale from 0 to 10), lives in a province with an unemployment rate of $8 \%$ and has average labor market monthly earnings of $1000 \mathrm{DM}$ in 1985 . We chose a benchmark of 8 years of experience in order to be 6 years below the potential number of years of experience. ${ }^{21}$ In this way, we model an immigrant who experienced periods of unemployment upon his arrival in the host country. We simulated predicted migration durations from 1985 onwards by simulating 10000 choice sequences for our marginal immigrant from 1985 to the time he exits the country, using the parameters reported in Table 2 . We then alter successively either one variable or parameter and compare the new distribution of predicted migration durations to the benchmark case.

Table 4 reports, for both the dynamic and myopic model, predicted total migration durations (all durations include 4 years since immigration assumed at the start in 1985) averaged over all simulations. The forward-looking model benchmark predicts an average migration duration of 14.95 years. We simulate a tax relief by permanently increasing the net average monthly labor market earnings of immigrants by the lump-sum value of $100 \mathrm{DM}$ per month. Our simulations show that this tax relief increases the migration duration by $65.75 \%$ to 24.78 years, a considerable increase relative to the amount given. Integration policies aimed at boosting human capital levels can take different forms. Governments can offer language courses to speed up proficiency of immigrants, or they may offer training which could raise the returns to labor market experience of immigrants. Both policies are predicted to have sizeable consequences for migration durations. Increasing speaking fluency from "Below average" to "Very good" increases migration duration by $71.51 \%$ to 25.64 years, which reflects that immigrants with better speaking fluency have higher expected earnings. Offering training courses which would raise the returns to labor market experience by $25 \%$ results in average migration durations of 29.83 years, almost twice that of the benchmark case. Alternatively, governments can reduce the barriers to entry in the host labor market by offering internships or other programs aimed at increasing an immigrant's labor market experience. Such a measure is simulated by increasing the number of years of labor market experience of our marginal immigrant in 1985 by 4 years. We find that the migration duration increases relatively less than all previous changes, increasing average duration by $34.18 \%$ to just above 20 years. Increasing the satisfaction with labor income from 3 to 6 on the scale has a surprisingly important impact on the migration durations, which average 30.22 years, $102.14 \%$ higher than the baseline case. Finally, returning money to the native country increases migration durations by $59.8 \%$ to an average of 23.89 years, which is consistent with the predictions of recent models of credit market rationing Mesnard (2001).

The results of table 4 focus on the mean of the predicted migration duration distributions. Because our simulations put an upper bound of 40 years on the possible migration duration, the comparisons described above may be affected by this censoring. Quantiles of the migration duration distribution on the other hand are robust to this type of censoring. For this reason, and also because our empirical model allows sufficient non-linearities with respect to accumulated labor market experience, it is of interest to investigate how other points of the migration duration distribution are affected by changes in the economic environment. Figure 3 presents the distribution of the simulated migration durations for some of the relevant cases discussed in Table 4. Interestingly, the distribution of the migration durations in the benchmark case is split between very low and very high durations. The migration duration probabilities decline rapidly between 4 and 20 years of stay in the host country. The probability that the migration duration lasts anywhere between 22 and 32 years is very small. However, we find a small increase in the probabilities of having migrations beyond 32 years, and a $12 \%$ probability that our marginal immigrant enters retirement age (after 40 years in the host country) while in Germany. The U-shape pattern of

\footnotetext{
${ }^{21}$ In this case, the number of potential years of experience are 30-10 years of education $-6=14$.
} 
the migration duration distribution is consistent with parameter estimates of the structural model discussed earlier. There, we found a U-shape relation between labor market experience and the utility of outmigration, which implies that both immigrants with the lowest and highest levels of labor market experience have a higher probability of outmigrating. It is interesting to see that the main impact of our comparative static exercises is to shift probability mass from the lower hand of the distribution to the upper hand, whiping out middle durations. The probability that our marginal immigrant reaches retirement age in Germany increases from $12 \%$ in the benchmark case to a little more than $40 \%$ in the case of a permanent tax relief of $100 \mathrm{DM}$. The effect of other changes are similar, all leading to substantial increases in the probability of reaching retirement age in Germany. One exception concerns increasing the number of years of labor market experience in 1985. We find that this lowers low migration durations but increases migration durations between 16 and 38 years, a change consistent with our parameter estimates which suggested that immigrants with more years of labor market experience suffer greater disutility from working in the host country, and lower disutility from outmigration.

The second column of Table 4 reports statistics for the same set of simulations, this time using the myopic model. The magnitude and directions of the comparative static effects differ enormously between both models. First, we find that the predicted average migration duration in the benchmark case are substantially lower, with an average duration of 6.19 years. This is consistent with the fact that myopic immigrants do not discount future utility changes as their economic position improves. Accordingly, we find that a tax relief of $100 \mathrm{DM}$ increases the average migration duration relative by $11.78 \%$ relative to the benchmark case, a little less than an extra year. Improvements in speaking fluency and returns to labor market experience have the same positive effect on migration duration than in the forward looking model but, again, of much smaller magnitude (raising migration durations by $12.92 \%$ and $15.99 \%$ respectively). The most surprising differences between the forward-looking model and the myopic model concerns the effect of increasing immigrant satisfaction with income and the effect of returning money to the native country. While increasing satisfaction with income doubled the average migration duration in the forward-looking model, it has virtually no effect (even has a small negative effect) on the migration durations in the myopic model. Similarly, while returning money increased migration durations by $59.79 \%$ in the forward-looking model, they are found to increase migration durations in the myopic model by only $2.56 \%$. The shape of the predicted migration durations in the myopic model is also very different from those of the forward-looking model. Figure 4 presents the simulated migration duration distributions for the myopic model. The benchmark distribution is heavily skewed to the left, and the probability of staying in Germany for longer than 26 years is in all practical sense zero. All other graphs have a similar shape and make clear that the myopic model predicts that our marginal immigrant would never enter retirement age in the host country, a clear distinction with the forward looking model.

\section{Conclusions}

This paper is a first attempt to estimate a structural dynamic model of work and outmigration decisions that immigrants make over their life-cycle. The optimization problem of immigrants has the structure of a dynamic programming problem, which can be solved recursively by backward induction. The model in this paper distinguishes itself from the existing literature by allowing immigrants to progressively revise their migration duration decisions during the migration period. Despite this difference, the model is general enough to incorporate several determinants of outmigration put forward in the existing literature, namely differences in earnings and marginal utilities of consumption between the home and host country, credit market rationing, feelings of social integration and satisfaction with income. The labor market earnings of immigrants are di- 
rectly incorporated in the model and estimated along with the choice data. The structure of our model allows us to estimate several popular measures of immigrant economic assimilation while controlling for sample selection biases due to the potential endogeneity in years of labor market experience and years since immigration, both of which evolve over time according to past work and outmigration decisions. We used panel attrition as a proxy variable for outmigration and corrected for the fact that part of the attrition does not lead to outmigration by extending to our dynamic programming setting the method proposed in Bellemare (2003). This allows us to make structural inferences on outmigration behavior in conjunction with work and earnings determination without properly observing outmigration decisions. The estimates of the model are used to predict changes in the life-cycle patterns of outmigration decisions due to changes in feelings of being integrated in the host country, income satisfaction, labor taxes, and returns to labor market experience. We estimate the model using the immigrant sample of the GSOEP, which contains a rich amount of information on the social and economic well being of immigrants during the 1985-1999 period. The model was shown to fit the data reasonably well.

Our parameter estimates indicate that commonly used measures of economic assimilation are very robust to endogenous work and outmigration choices. Part of the robustness can be attributed to the low outmigration rates predicted by the model. Indeed, our model predicts an outmigration rate of $3 \%$ per year, with very little cyclical fluctuations across the time period observed. We suspect that the magnitude of the endogeneity bias may be higher in data sets subject to higher outmigration rates, as long as outmigrants are clearly selected from either the top or (in the case of the current paper) from the bottom of the immigrant earning distribution. Because estimates of assimilation rates can directly influence the development of new immigration policies, verification of this hypothesis using other data sets within a framework similar to the one presented here will be an important task for future research.

Our findings confirm the hypothesis recently put forward in the literature that outmigration is not entirely driven by earnings differentials. Specifically, we find that immigrants who feel integrated in the German society, those who are satisfied with their income, and those who return money to their native country are less likely to outmigrate. The results of this paper also highlighted the importance of incorporating the work decision along with the migration duration decision of immigrants, a feature previously ignored in the outmigration literature. We found that both immigrants with relatively low and high labor market experience have a greater overall utility of outmigration, which suggests a $U$ shape relation between labor market experience and the overall utility to outmigrate. The decrease in overall outmigration utility starting from low levels of experience is consistent with increasing psychic costs associated with outmigration, keeping earnings constant. The convex increase in overall outmigration utility predicted to occur beyond 25 years of labor market experience is consistent with progressively lower psychic costs of outmigration and diminishing returns to labor market experience in the host country. These results are interesting given that most of the outmigration literature has analyzed outmigration within an earnings differential paradigm which, by construction, orient policy recommendations towards measures aimed at influencing the earnings differential between the host and home country. Clearly our results do not rule out the important role played by labor market earnings in determining migration durations. However, they do indicate that the shape of the migration duration distribution is determined by past work decisions, indicating that much can be gained from an analysis in which work decisions are endogenously determined. Moreover, the foregoing analysis indicates that policies aimed at improving access of immigrants to the host labor market upon their arrival may also play an important role in determining migration durations.

The bimodal shape of the migration duration distribution was found to be robust to realistic changes in model parameters. Our simulation results indicate that changes in the economic envi- 
ronment have strong repercussions on migration durations of immigrants at the margin between staying in Germany and leaving, suggesting that small policy changes may lead these immigrants to substantially revise their intended migration duration. Because immigrants in our sample discount substantially the future, the impact of several policy changes on predicted migration durations based on a forward looking model are found to be much more sensitive to changes in the economic environment as opposed to a purely static, myopic model. Moreover, the predicted migration duration distribution in the myopic model is unimodal, suggesting that immigrants at the margin between staying in Germany and leaving would never establish themselves permanently in the host country, a feature in sharp contrast with the predictions of the forward-looking model. These results illustrate the need for a careful evaluation of immigrant subjective discount rates when discussing the impact of policy changes.

Finally, this paper has shown that the approach used to separate outmigration from attrition performs well in the structural setting developed in this paper. Estimates of the probability of confounding immigrants who leave the panel but remain in the host country with outmigrants were found to be robust to the structural specification, and gave practically identical values to those reported in the reduced form model of Bellemare (2003), an indication that they are relatively well identified. As several panel data sets follow immigrants over time but almost none of them possess information on micro-level outmigration decisions, we hope that this paper is a first step towards more structural tests of life-cycle models of outmigration behavior. 


\begin{tabular}{lccl}
\hline \hline & & & \\
\cline { 2 - 3 } & 1985 & 1999 & Variable description \\
Age & 39.78 & 44.53 & \\
Experience & 24.49 & 27.81 & Number of years of labor market experience \\
Education & 9.34 & 10.04 & Number of years \\
Income satisfaction & 6.14 & 5.80 & $0=$ unsatisfied,...,10 totally satisfied \\
Wife in Germany & 0.73 & 0.01 & 1 if yes, 0 otherwise \\
Integration feeling & 3.94 & 2.93 & Do you feel German ?, 5=Totally, ...,1=Not at all \\
German speaking fluency & 2.65 & 2.30 & $1=$ bad, $5=$ excellent \\
Intended length of stay & 2.18 & 0.59 & $1=$ Within 1 year, $2=$ After a few years, $3=$ Never \\
Age at immigration & 24.03 & 24.90 & \\
Years since immigration & 15.75 & 19.63 & \\
Immigration year & 1969 & 1979 & \\
& & & \\
Number Obs. & 732 & 393 & \\
& & & \\
\hline \hline
\end{tabular}

Table 1: Descriptive statistics, 1985 and 1999 


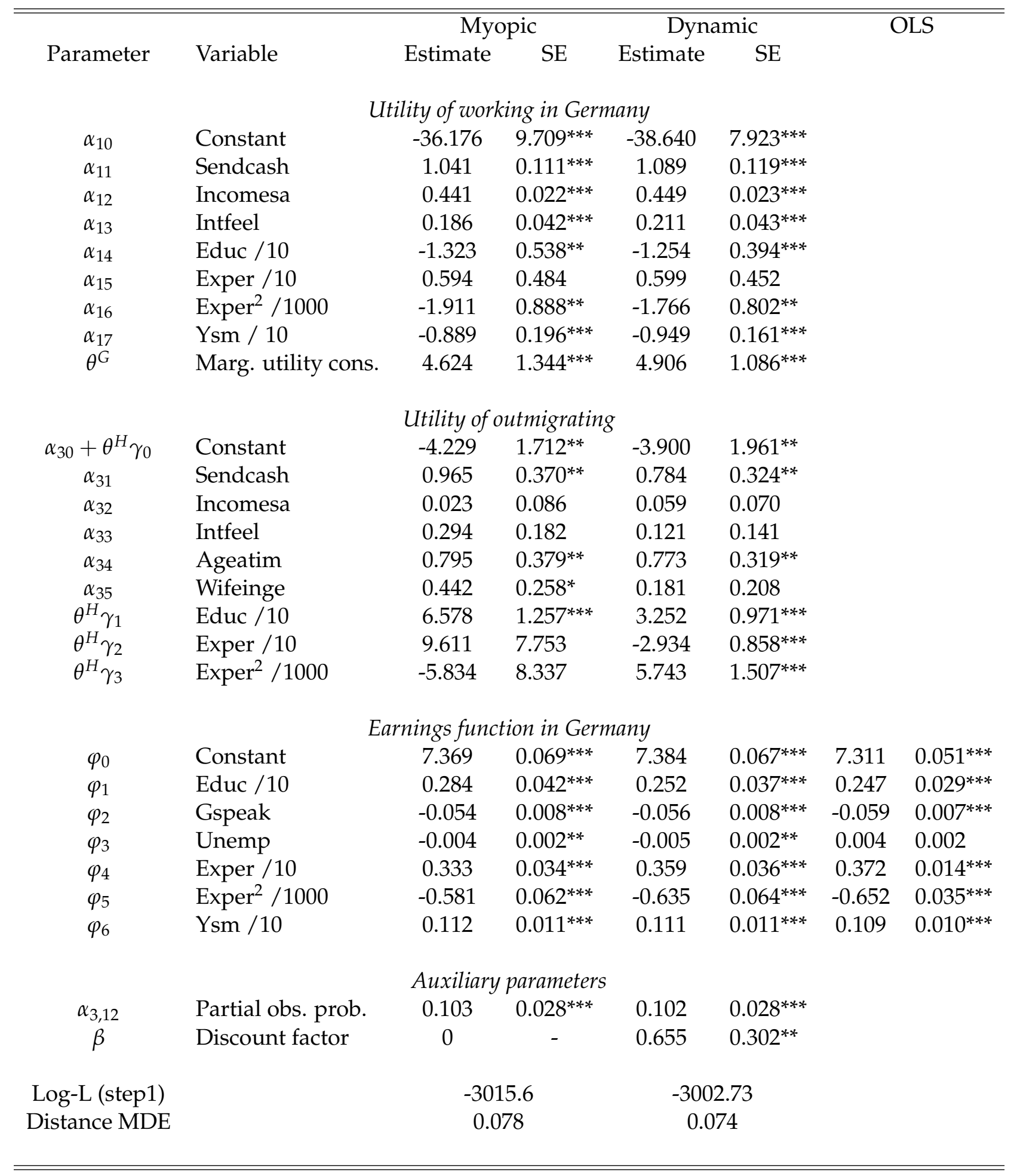

Table 2: Minimum distance estimation of structural model. Asymptotic standard errors in parenthesis. ${ }^{* * *}$ denotes significance at 1 


\begin{tabular}{|c|c|c|c|c|c|c|}
\hline & \multicolumn{3}{|c|}{ West-Germans } & \multicolumn{3}{|c|}{ Immigrants } \\
\hline & $\mathrm{N}$ & \% 1985 & Attrition rate & $\mathrm{N}$ & \% 1985 & Attrition rate \\
\hline 1985 & 1987 & 100 & - & 732 & 100 & - \\
\hline 1987 & 1648 & 82.9 & 17.1 & 583 & 79.6 & 20.4 \\
\hline 1989 & 1408 & 70.8 & 14.6 & 473 & 64.6 & 18.9 \\
\hline 1991 & 1253 & 63.1 & 11.0 & 416 & 56.8 & 12.1 \\
\hline 1993 & 1122 & 56.4 & 10.5 & 355 & 48.4 & 14.7 \\
\hline 1995 & 1002 & 50.4 & 10.7 & 291 & 39.7 & 18.0 \\
\hline 1997 & 919 & 46.3 & 8.3 & 242 & 33.1 & 16.8 \\
\hline 1999 & 834 & 41.9 & 9.3 & 195 & 26.7 & 19.4 \\
\hline Mean 1985-1999 & & & 11.6 & & & 17.2 \\
\hline
\end{tabular}

Table 3: Panel attrition for West-German and Immigrant samples 1985-1999. 


\begin{tabular}{lcccc}
\hline \hline & & & & \\
& \multicolumn{2}{c}{$\beta=0.655$} & & \multicolumn{2}{c}{$\beta=0$} \\
& Mean & $\%$ with baseline & Mean & $\%$ with baseline \\
Baseline & 14.95 & - & 6.19 & - \\
100 DM per month extra & 24.78 & 65.75 & 6.92 & 11.78 \\
Speaking fluency "Very good" & 25.64 & 71.51 & 6.99 & 12.92 \\
Satisfaction with income 6 out of 10 & 30.22 & 102,14 & 6.47 & 4.56 \\
Returns to experience 25\% higher & 29.83 & 99.53 & 6.18 & 15.99 \\
Labor market experience 4 years higher & 20.06 & 34.18 & 6.39 & 3.23 \\
Returning money to native country & 23.89 & 59.79 & 6.35 & 2.56 \\
& & & & \\
\hline \hline
\end{tabular}

Table 4: Simulated migration durations in years. Baseline represents as a 30 year old immigrant, who migrated to Germany four years ago, has 10 years of education, 8 years of experience, does not return money to his native country, speaks below average German (4 on the scale from 1 to 5), is not married, has a reported satisfaction with income of 3 (on the scale from 0 to 10), lives in a province with unemployment rate of 8 


\begin{tabular}{|c|c|c|c|c|c|}
\hline \multirow[b]{2}{*}{ Parameter } & \multirow[b]{2}{*}{ Variable } & \multicolumn{2}{|c|}{ Myopic } & \multicolumn{2}{|c|}{ Dynamic } \\
\hline & & Estimate & SDE & Estimate & SDE \\
\hline$\lambda_{10}$ & Constant & -1.203 & $0.426^{* *}$ & -1.804 & $0.543^{* * *}$ \\
\hline$\lambda_{11}$ & Sendcash & 0.999 & $0.112^{* * *}$ & 1.045 & $0.121^{* * *}$ \\
\hline$\lambda_{12}$ & Incomesa & 0.428 & $0.022^{* * *}$ & 0.435 & $0.023^{* * *}$ \\
\hline$\lambda_{13}$ & Intfeel & 0.108 & $0.044^{* *}$ & 0.118 & $0.046^{* *}$ \\
\hline$\lambda_{14}$ & Educ /10 & 0.034 & 0.248 & 0.039 & 0.254 \\
\hline$\lambda_{15}$ & Gspeak & -0.191 & $0.061^{* * *}$ & -0.204 & $0.063^{* * *}$ \\
\hline$\lambda_{16}$ & Unemp & -0.091 & $0.018^{* * *}$ & -0.096 & $0.019^{* * *}$ \\
\hline$\lambda_{17}$ & Exper /10 & 2.090 & $0.178^{* * *}$ & 2.555 & $0.321^{* * *}$ \\
\hline$\lambda_{18}$ & Exper $^{2} / 1000$ & -4.541 & $0.324^{* * *}$ & -5.157 & $0.516^{* * *}$ \\
\hline$\lambda_{19}$ & Ysm /10 & -0.392 & 0.075 & -0.442 & $0.078^{* * *}$ \\
\hline$\lambda_{30}$ & Constant & -14.467 & 19.806 & -6.239 & $2.386^{* *}$ \\
\hline$\lambda_{31}$ & Sendcash & 0.571 & 0.388 & 0.626 & $0.332^{*}$ \\
\hline$\lambda_{32}$ & Incomesa & 0.089 & 0.091 & 0.094 & 0.071 \\
\hline$\lambda_{33}$ & Intfeel & 0.275 & 0.182 & 0.166 & 0.143 \\
\hline$\lambda_{34}$ & Ageatim & 0.437 & 0.418 & 0.549 & 0.338 \\
\hline$\lambda_{35}$ & Wifeinge & 0.420 & $0.258^{*}$ & 0.147 & 0.209 \\
\hline$\lambda_{36}$ & Educ /10 & 5.254 & $1.354^{* * *}$ & 2.786 & $0.976^{* *}$ \\
\hline$\lambda_{37}$ & Exper /10 & -1.505 & 8.529 & -1.338 & 1.021 \\
\hline$\lambda_{38}$ & Exper $^{2} / 1000$ & 5.768 & 9.339 & 3.586 & $1.609^{* *}$ \\
\hline$\alpha_{3,12}$ & Partial obs. prob. & 0.117 & $0.033^{* * *}$ & 0.112 & $0.031^{* * *}$ \\
\hline$\beta$ & Discount factor & 0 & - & 0.618 & $0.342^{*}$ \\
\hline Log-L & & \multicolumn{2}{|c|}{-3015.6} & \multicolumn{2}{|c|}{-3002.73} \\
\hline$\varphi_{0}$ & Constant & 7.754 & $0.220^{* * *}$ & 7.568 & $0.242^{* * *}$ \\
\hline$\varphi_{1}$ & Educ / 10 & 0.229 & $0.045^{* * *}$ & 0.240 & $0.037^{* * *}$ \\
\hline$\varphi_{2}$ & Gspeak & -0.054 & $0.008^{* * *}$ & -0.054 & $0.008^{* * *}$ \\
\hline$\varphi_{3}$ & Unemp & 0.007 & $0.003^{* *}$ & 0.007 & $0.003^{* *}$ \\
\hline$\varphi_{4}$ & Exper / 10 & 0.367 & $0.050^{* * *}$ & 0.349 & $0.048^{* * *}$ \\
\hline$\varphi_{5}$ & Exper / 1000 & -0.669 & $0.102^{* * *}$ & -0.622 & $0.097^{* * *}$ \\
\hline$\varphi_{6}$ & Ysm / 10 & 0.126 & $0.011^{* * *}$ & 0.126 & $0.011^{* * *}$ \\
\hline$\tau_{2}$ & Work selection & 0.239 & $0.091^{* *}$ & 0.169 & $0.101^{*}$ \\
\hline$\tau_{3}$ & Outmigration selection & -0.038 & $0.009^{* * *}$ & -0.044 & $0.009^{* * *}$ \\
\hline
\end{tabular}

Table 5: Maximum likelihood estimates of reduced form model. Asymptotic standard errors in parenthesis. ${ }^{* * *}, * * *$ denote respectively significance at the 10,5 and 1 percent level 


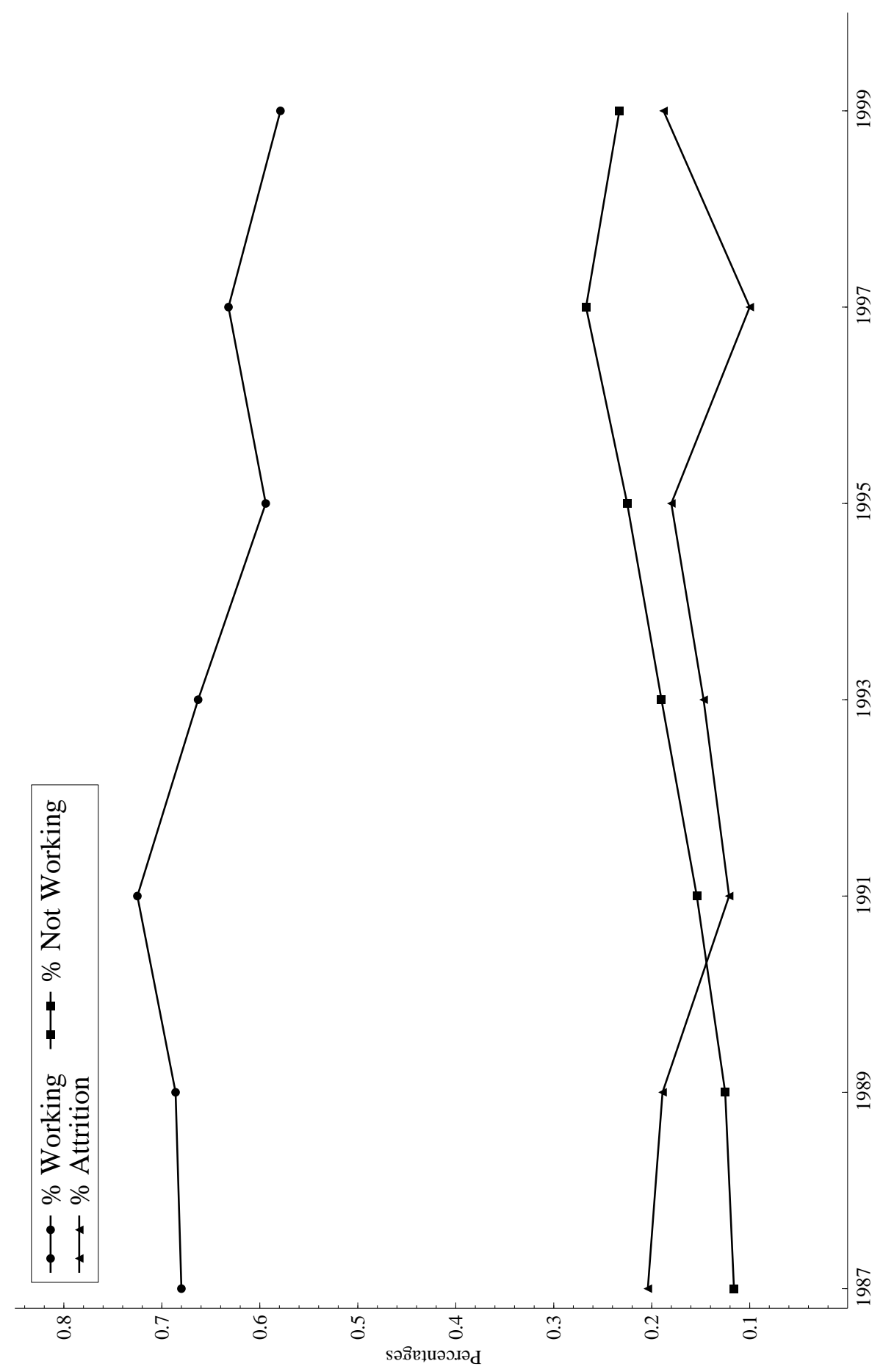

Figure 1: Proportions of immigrants working in Germany, not working and attrition per time period, 1987-1999. 

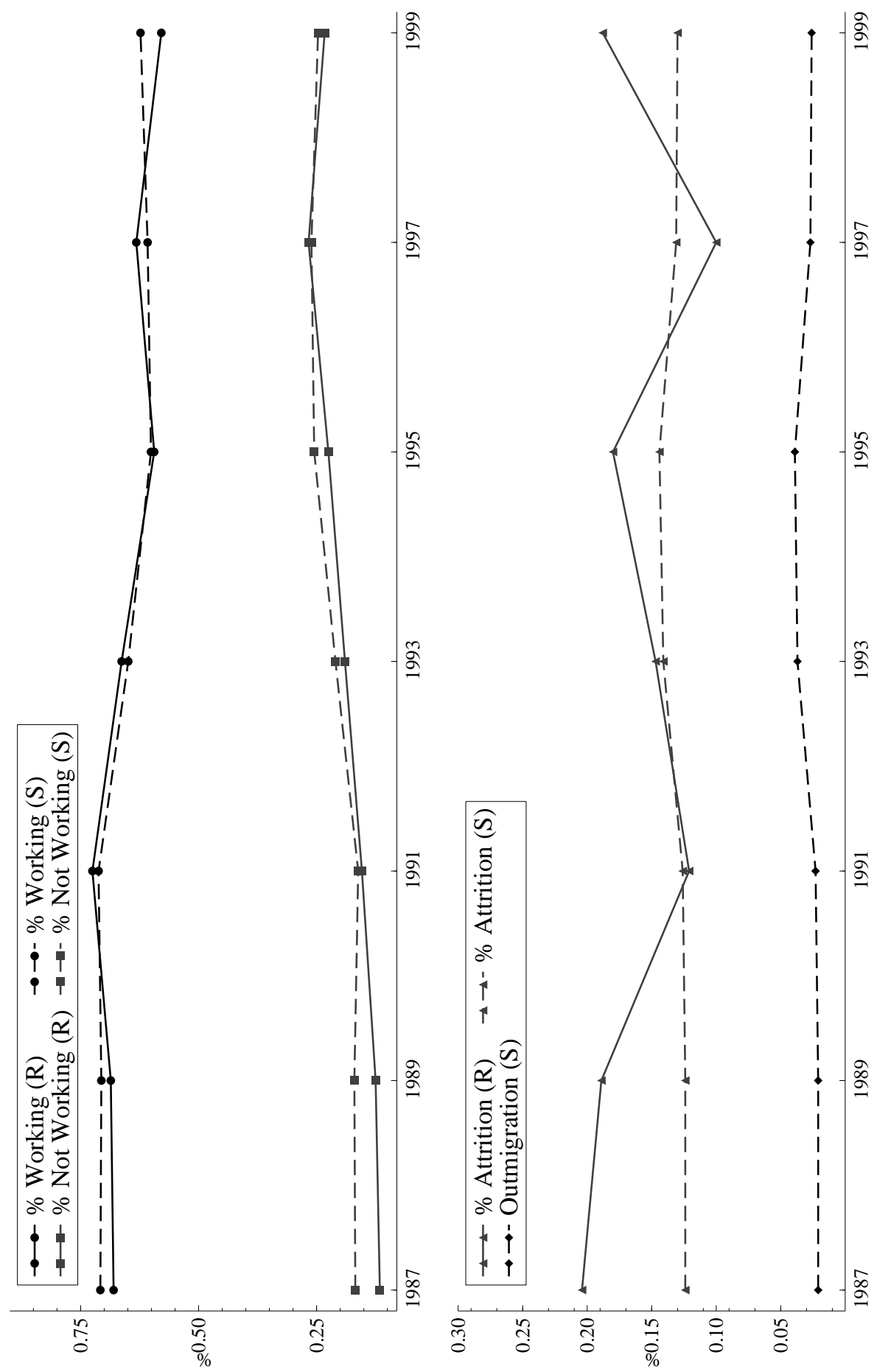

Figure 2: Goodness of fit of the model. Real (R) and simulated (S) frequencies of each alternative over the 1987 and 1999 period. Simulations are performed by taking for each individual and each time period 1000 draws from the extreme-value distribution. The simulations are obtained by averaging over individuals and draws the predicted frequency of each choice. 

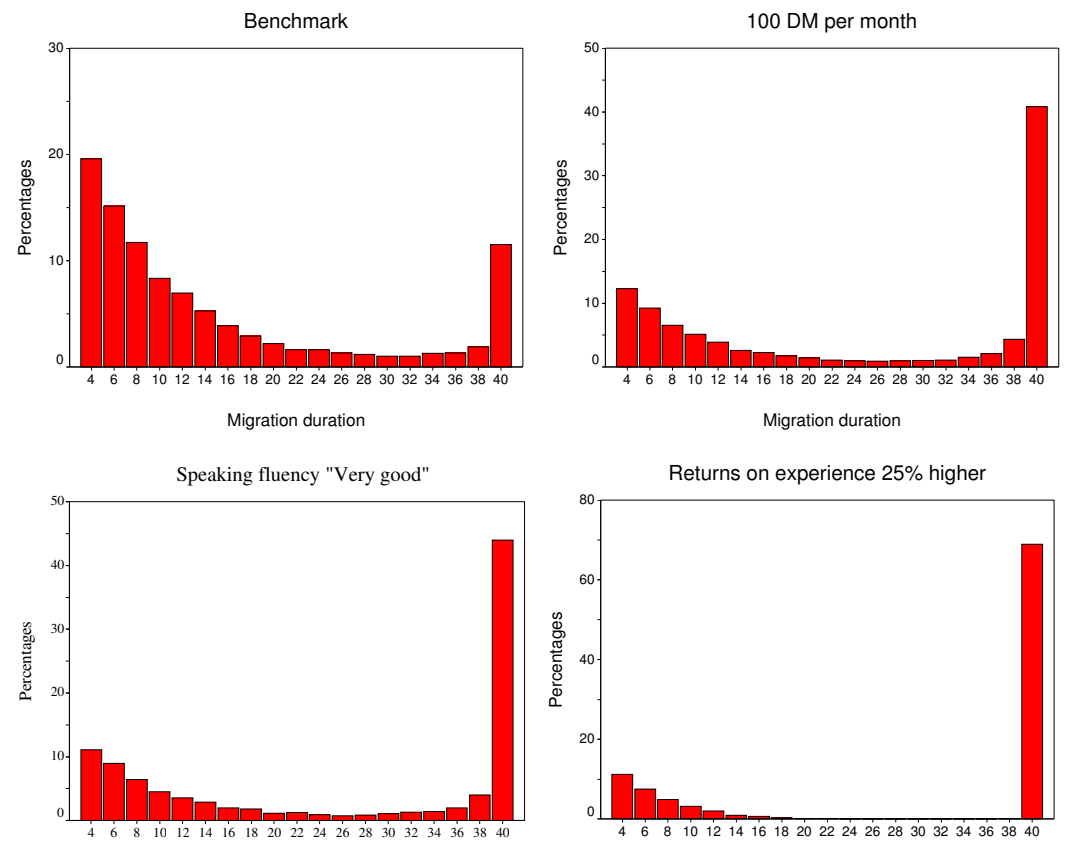

Migration duration

Migration duration
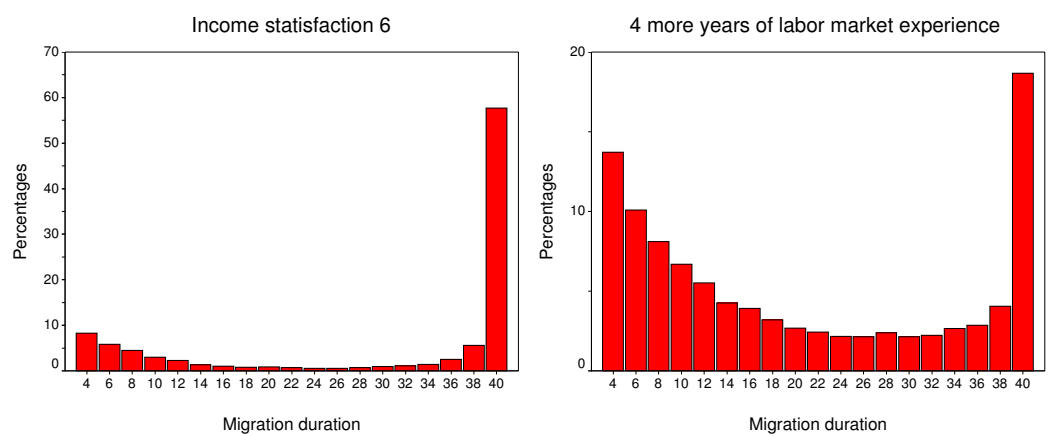

Figure 3: Simulated distributions for the forward looking model. Percentages are obtained by simulating 10000 choice sequences and averaging the predicted migration durations over all sequences. Benchmark is a 30 year old immigrant, who migrated to Germany four years ago, has 10 years of education, 8 years of experience, does not return money to his native country, speaks below average German ( 4 on the scale from 1 to 5 ), is not married, has a reported satisfaction with income of 3 (on the scale from 0 to 10), lives in a province with unemployment rate of $8 \%$ and has an average earnings of $1000 \mathrm{DM}$. 

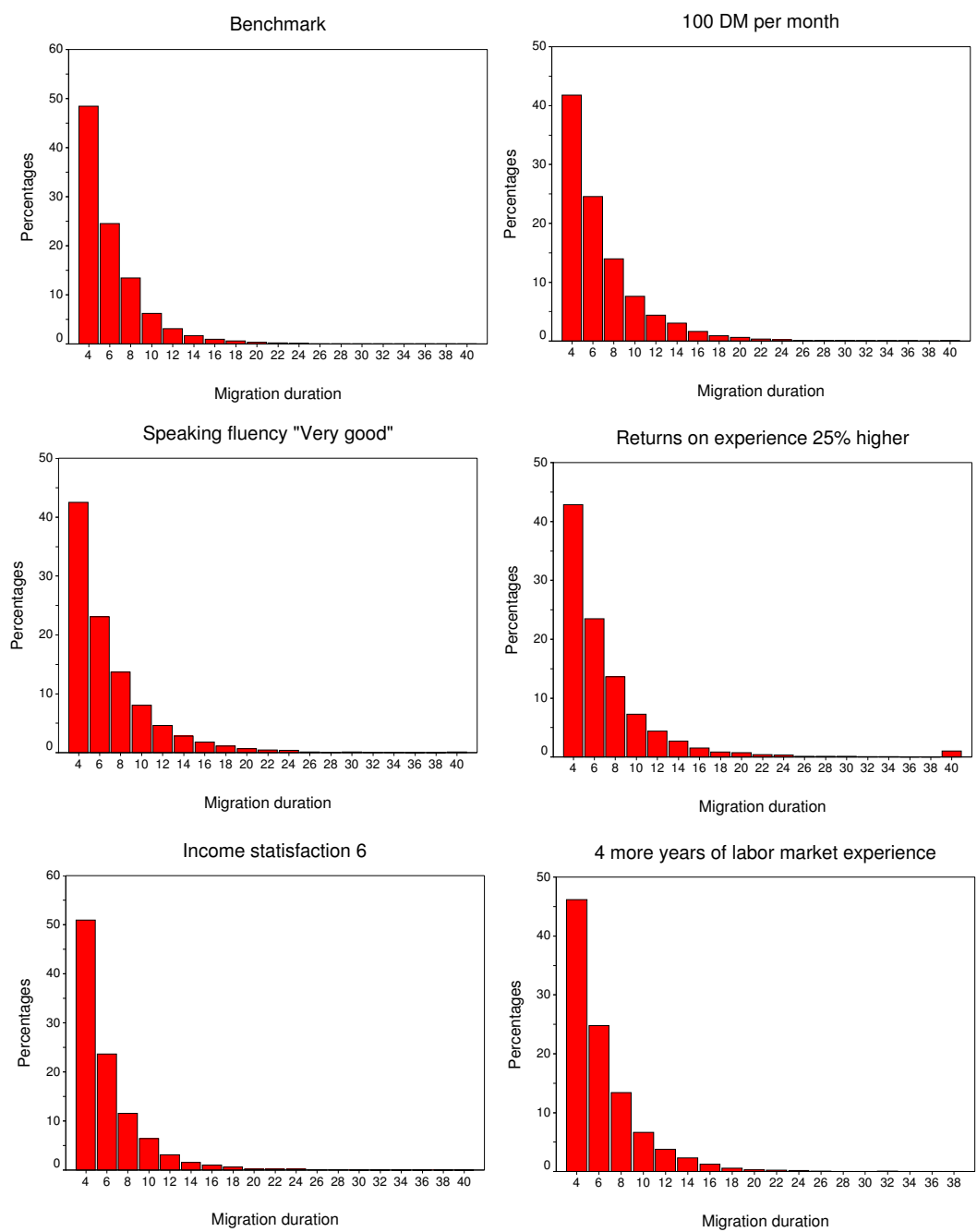

Figure 4: Simulated distributions for the myopic looking model. Percentages are obtained by simulating 10000 choice sequences and averaging the predicted migration durations over all sequences. Benchmark is a 30 year old immigrant, who migrated to Germany four years ago, has 10 years of education, 8 years of experience, does not return money to his native country, speaks below average German ( 4 on the scale from 1 to 5 ), is not married, has a reported satisfaction with income of 3 (on the scale from 0 to 10), lives in a province with unemployment rate of $8 \%$ and has an average earnings of $1000 \mathrm{DM}$ 


\section{References}

Bellemare, C. (2003): "Identification and Estimation of the Economic Performance of Outmigrants Using Panel Attrition," Working paper, CentER, Tilburg University.

Bellman, R. (1957): Dynamic Programming. Princeton University Press, Princeton.

BÖHNING, W. (1987): Studies in International Migration. St. Martin's Press, New-York.

Bound, J., C. BRown, And N. Mathiowetz (2001): Measurement Error in Survey Datavol. 5 of Handbook of Econometrics, chap. 59, pp. 3707-3843. Elsevier Science B.V.

Carrington, W. J., E. Detragiache, and T. Vishwanath (1996): “Migration with Endogenous Moving Costs," American Economic Review, 86(4), 909-930.

Chamberlain, G. (1984): Panel Datavol. 2 of Handbook of Econometrics, chap. 22, pp. 1248-1318. North-Holland.

Clark, W. A., AND A. I. Drever (2001): “Do Immigrants Improve their Housing Quality When They Move ? Evidence from the German Socio-Economic Panel," Vierteljahrshefte Zur Wirtschaftsforschung, 70, 87-94.

COHEN, S., AND Z. ECKSTEIN (2002): “Labor Mobility of Immigrants: Training, Experience, Language and Opportunities," Working paper, Tel-Aviv University.

DJAJIC, S., AND R. MilbouRne (1988): “A General Equilibrium Model of Guest Worker Migration," Journal of Internation Economics, 25, 335-351.

DubiN, J., AND D. MCFAdDEn (1984): “An Econometric Analysis of Residential Electric Appliance Holdings and Consumption," Econometrica, 52, 345-362.

DustMAnN, C. (1994): “Return Intentions of Migrants: Theory and Evidence," Discussion paper, CEPR Discussion paper no. 906.

_ (1996): "Return Migration, the European Experience," Economic Policy, pp. 215-250.

(2003): "Return migration, wage differentials, and the optimal migration duration," European Economic Review, 47, 353-369.

EDIN, P.-A., R. J. LALONDE, AND O. ASLUND (2000): “Emigration of Immigrants and Measures of Immigrant Assimilation: Evidence from Sweden," Swedish Economic Policy Review, 7, 163-204.

Glytsos, N. P. (1988): “Remittances and Temporary Migration: A Theoritical Model and its Testing with the Greek-German Experience," Weltwirtschafliches Archiv, 124, 524-549.

HARRIS, J. R., AND M. P. TODARO (1970): “Migration, Unemployment, and Development: A Two-Sector Analysis," American Economic Review, 60, 126-142.

HU, W.-Y. (2000): "Immigrant Earnings Assimilation: Estimates from Longitudinal Data," American Economic Review, 90(2), 368-372.

Jasso, G., And M. R. RosenzWeIG (1990): "Selef-Selection and the Earnings of Immigrants: Comment," American Economic Review, 80(1), 298-304.

LALONDE, R. J., AND R. H. TOPEL (1992): “The Assimilation of Immigrants in the U.S. Labor Market," in Immigration and the Workforce: Economic Consequences for the United States and Source Areas, ed. by G. J. Borjas, and R. B. Freeman, pp. 67-92, Chicago. University of Chicago Press. 
LUBotsky, D. (2000): “Chutes or Ladders ? A Longitudinal Analysis of Immigrant Earnings," Working paper, University of Illinois at Urbana-Champaign.

Magnac, T., And D. Thesmar (2002): “Identifying Dynamic Discrete Decision Process," Econometrica, 70, 801-816.

MANSKI, C. F. (2003): “Inference on Dxpectations and Decisions,” Working paper, Northwestern University.

MESNARD, A. (2001): “Temporary Migration and Capital Market Imperfections," ARQADE Working paper, University of Toulouse 1.

PAnNenberG, M. (1998): "Documentation of Sample Sizes and Panel Attrition in the German Socio Economic Panel," DIW Discussion Paper No. 172.

PessinO, C. (1991): "Sequential Migration Theory and Evidence from Peru," Journal of Development Economics, 36, 55-87.

PisCHKE, J.-S., AND J. Velling (1997): "Employment Effects of Immigration to Germany: An Analysis Based on Local Labor Markets," Review of Economics and Statistics, 79, 594-604.

Rust, J. (1988): "Maximum Likelihood Estimation of Discrete Control Processes," SIAM Journal on Control and Optimization, 26, 1006-1023.

(1994): Structural Estimation of Markov Decision Processeschap. 51, pp. 3081-4143, Handbook of Econometrics. Amsterdam: Elsevier Science, North-Holland Publishers.

SCHultz, T. P. (1998): "Immigrant Quality and Assimilation - A Review of the US Literature," Journal of Population Economics, 11(2), 239-252.

SJAASTAD, L. (1962): “The Coststs and Returns of Human Migration," Journal of Political Economy, 70(Suppl.), 80-93.

STARK, O. (1998): On the Microeconomics of Return Migrationchap. 3, pp. 32-41.

VAN DER KlaAuW, W. (1996): "Female Labour Supply and Marital Decisions: A Life-Cycle Model," Review of Economic Studies, 63(2), 199-235.

ZimmermanN, K. F. (1995): “Tackling the European Migration Problem," Journal of Economic Perspectives, 9(2), 45-62. 